\title{
Impacts of digitization on real estate sector jobs
}

\author{
Daniel Piazolo and Utku Cem Dogan \\ Technische Hochschule Mittelhessen, Friedberg, Germany
}

\begin{abstract}
Purpose - Previous research on automation and job disruption is only marginally related to the real estate industry and its characteristics. This study investigates the effects of digitization on jobs in German real estate sector, in order to assess the proportion of jobs threatened to be replaced by automation. Since Germany is the largest EU economy insights for the German real estate market allow a first approximation for Europe.

Design/methodology/approach - An extensive database of the German Federal Employment Agency containing job definitions and occupation titles is matched with real estate criteria to create a subset with the relevant real estate occupations. This data is combined with a database of the German Institute of Employment Research reflecting to what extent tasks within jobs can be automated by current technical capabilities.

Findings - For the 286 identified occupations within the real estate sector a weighted average of 47 percent substitution probability through current technological capabilities is derived for tasks within the examined occupations.

Practical implications - This contribution indicates the extent of the structural change the real estate sector has to face due to digitization: One out of two real estate jobs will have to be re-created.

Originality/value - This research quantifies the magnitude of the job killer aspect of digitization in the real estate sector.
\end{abstract}

Keywords Employment, Digitization, Automation, Structural change, Disruption, Substitution potential

Paper type Research paper

\section{The challenge for jobs}

When the popular media routinely run article titles like "A World Without Work" (Thompson, 2015), there is a strong indication that an issue has reached a significant level of critical mass. There is no disputing that new technologies (NT) are disrupters to labor and vocational categories, however, the levels of disruption and its impact are not agreed on. At the same time, the utilization of NT's leads to new possibilities and job areas that are being created. These jobs differ in their complexity and demands, and therefore are often better paid.

Innovation and its impact on labor is part of structural change. Pessimistic views in the last year are frequently based on insights from Frey and Osborne (2013) who quantified the impacts of NT's on labor markets in the United States. Accordingly, 47 percent of jobs are subject of being substituted by NT's until 2030. Various studies have used the results of Frey and Osborne by transferring the codes of American occupations to other countries (Bonin et al., 2015; Dengler and Matthes, 2015; Brzeski and Burk, 2015), according to the International Standard Classification of Occupations (ISCO). However, these studies follow the approach that it is not entire professions that can be replaced by NT's, but rather activities leading to a significantly lower share of jobs that are being threatened to be substituted by computers. Arntz et al. (2017) maintain that there is evidence to support an impact of a 9 percent to 11 percent job loss in OECD countries caused by digitization. For the purpose of serving as a

(C) Daniel Piazolo and Utku Cem Dogan. Published by Emerald Publishing Limited. This article is published under the Creative Commons Attribution (CC BY 4.0) licence. Anyone may reproduce, distribute, translate and create derivative works of this article (for both commercial and non-commercial purposes), subject to full attribution to the original publication and authors. The full terms of this licence may be seen at http://creativecommons.org/licences/by/4.0/legalcode

This paper forms part of a special section "PropTech and Entrepreneurship - Innovation in Real Estate II", guest edited by Dr Larry Wofford, Dr David Wyman, Dr Elaine Worzala.
Digitization and German real estate jobs

Received 27 September 2019 Revised 18 December 2019 Accepted 19 December 2019

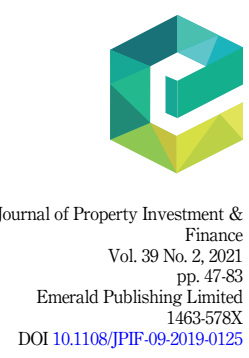


JPIF

39,2

literature review to a wider study that specifically aims at the impact of NT's on real estate, the focus of the following will ask whether there is anything emergent about the current transformations and a long history of previous disruptive phases.

Wage stagnation has been an important economic force that has occurred steadily since the 1980's among Organization for Economic Co-operation and Development (OECD) nations. Stagnation means that wages are relatively flat and do not rise at the rate of inflation. Among these OECD countries, this is a reversal of economic trends that have defined most of the Twentieth Century and was accelerated in particular, during the post-World War Two period. It is a period where the most prominent factor of this trend is that each subsequent generation had more wealth and disposable income than the previous. The consequence of this stagnation is that little growth is occurring and lower relative wages means that capital is not circulating in the economy given that people simply have less disposable income to spend (Picketty, 2014). The economy has stagnated, but capital or profit has increased and this is explained through fewer workers creating more profit and also, a shift toward the financialization of the economy. At the same time, Gregory et al. (2016) conclude that from 2000 to 2010 there has been a steady increase in labor demand. In spite of this shift on the other hand, rising unemployment has not been an outcome through the processes of automation that have occurred so far (Arntz et al., 2017). Within the context of Artificial Intelligence (AI), Machine Learning (ML) and robotics, these general factors raise a number of important variables for consideration because they make the impact of these new technologies difficult to measure.

When the data concerning wage stagnation is combined with the analysis of large sets of tax returns in the US and France over a fifty-year period (Picketty, 2014), a number of competing theories emerged as plausible explanation for this. One theory was that through the erosion of the bargaining power of labor wages have stagnated. A second major theory was that outsourcing of tasks and globalization of production are the most significant drivers of stagnation. Manufacturing and then service sector jobs have continually been moved from developed economies to emerging economies because of lower standards for regulation (Addo, 2016). After a period of stagnation being explained by theories about bargaining power shifts and globalization, a new set of evidence began to present NT's as the most important driver to this trend. However, the wider use of NT has various, mutually conflicting consequences. Variables of influence like globalization and political policies, cannot be completely separated from NT's as a factor for job loss and the de-skilling of labor which has resulted in lower wage forms of employment. Frey and Osborne (2017) assert that this creates a greater "polarization" between skilled and unskilled labor and therefore "a hollowing-out of middle-income jobs".

The following will examine the level of disruption on the real estate sector in particular. There is an important and conflicting set of assumptions and conclusions that make this difficult to determine. For reasons that will be outlined in the Literature Review, this study will take the task-based approach to automation or substitution potential defined by Dengler and Matthes, 2015, 2016 in order to determine the share of jobs in the German real estate industry that are affected by digitization. The article concludes with a discussion on the remaining tasks for human beings in the real estate industry.

\section{Literature review}

NT's can be understood as having a long history within the capitalist economy. The mechanization of labor can be traced to the steam powered machines that replaced hand weaving in the clothing industry in the late 1700's and early 1800's. This economic transformation to industrialization also contributed to an early reactionary backlash, which led to protests by workers in England between 1811 and 1816 when these new machines were blamed for unemployment and low wages. Consequently, the manufacturing equipment was damaged by workers (DeCanio, 2016; Frey and Osborne, 2017). Industrialization and 
automation were furthered when the Ford model of production was invented and then, quickly adopted by other types of industries. Henry Ford introduced the assembly line model of production whereby individuals become specialized in only one area of manufacturing and this division of labor made production more streamlined and created greater output. The automation of tasks and the deskilling of labor are not new. Like-wise, neither is the criticism of automation that has historically been based on the loss of employment and the de-skilling of existing work tasks. However, the counterweight to this trend has been the economic gains that have emerged as a result. Various areas of employment have been created by the technological change that has led to an expansion of entire sectors such as electronics and computer related fields. For example, Bessen (2016) presented a comprehensive data set of 317 types of jobs that were being replaced by automated technologies driven by computerization and demonstrated that newly created types of employment far exceeded the losses caused by automation. Based on the structure of industrialization within a historical context, DeCanio (2016) presents a data analysis of tasks and substitution potential, and concludes that wage levels will decrease, and that although NT's create new opportunities in fields like engineering, the overall outcome will be the de-skilling of labor.

There are a number of criticisms to this historically driven approach to job market changes. An important criticism of is related to market capitalization and value creation. West (2018) looks at the relationship between market capitalization and employment and compares data taken from 1962 to 2017. In 1962 the two largest companies in terms of market value were AT\&T with a value of USD\$ 20B (2017) with 564,000 employees and General Motors with a USD\$12B (2017) value and 605,000. In 2017, Apple had a market capital share of USD $\$$ 800B with 116,000 employees and Google/Alphabet had USD\$ 670B and 73,992 workers. In other terms, Apple generated forty times the wealth as AT\&T with a fifth of the full-time employees (West, 2018). As a good example of this wealth generation process achieved by few, two individuals developed Android with less than $\$ 10,000$ and then sold this in less than a year to Google for a $\$ 1 \mathrm{~B}$ and at the point of sale they employed 50 individuals (Madridakis, 2017). While some maintain that more jobs have been created by the overall computerization (Bessen, 2016), there are important features in current technologies that have to be considered for future projections. Although in the past there was a link between employment growth and innovation, in the future other factors specific to new technologies might generate value without employment growth.

AI can be seen as an example of different value creation in the context of social media and the platform economy. In 2017, Facebook had a market value of USD $\$ 441 \mathrm{~B}$ with 18,770 employees (West, 2018). The Facebook revenue was generated through the use of clients' data for the purposes of generating advertising, marketing and market research, and the means for this was the AI employed in data mining/collection and data-analytics. Plat-form models are achieving the same by having algorithms and not humans connect customers with service providers and then, collecting a fee through this human-less transaction. Facebook's market value to employee ratio is significantly greater than either Apple or Google.

Within the real estate industry, the platform economy and the use algorithms is likewise growing. Conway (2018) identifies nine major industry areas where 71 software applications and web-based platforms are emerging that replace human tasks and occupations. A number of these real estate areas include data analytics and platform applications that connect buyers and sellers, borrowers and lenders, customers and legal documents, customers and valuations. These areas are data driven $\mathrm{AI}$ applications, thus algorithms rather than people generate value.

Other areas are using more NT's and change the tasks performed by the human employees. The fastest growing area is buildings and operations management where remote security systems, smart home technologies and robotics used in cleaning and maintenance are already having a significant impact. Further, new possibilities emerge through 3D 
JPIF

39,2

technologies employed in viewing properties and through 3D printing. Thus an image can be quickly generated into an entire model of a building or a neighborhood area. Companies-like Doxel, OpenSpace, and Airworks specialize in digital photo-capturing buildings and construction sites by having cameras that are fixed, mounted on robots, on drones and construction worker hats (Conway, 2018). Conway identifies how NT's including AI, machine learning and big data create opportunities in the real estate sector because of their positive results in data-gathering, distribution, and analytics, automated valuation models, risk assessment, communications, and business processes. Furthermore, that are additional emergent areas such as Augmentation and Space Planning, Geospatial Analytics, and the internet of Things (IoT). Augmentation and Space Planning is the use of video capturing to create accurate 3D-ready spatial/building information. Geospatial Analytics includes how this data is processed into 3D-models, drawings, or animated formats. Conway (2018) defines this emerging real estate processes in the following terms: "Geospatial analysis is the gathering, display, and manipulation of imagery, GPS, satellite photography and historical data, described explicitly in terms of geographic coordinates or implicitly, in terms of a street address, postal code, or forest stand identifier as they are applied to geographic models" (Conway, 2018, p. 47).

Deloitte (2018) shows that the real estate service of the future must move away from the pure operational management of the buildings to a holistic approach that ensures that the customers are able to function.

Where some tasks such as a telephone dispatcher who would have conventionally connected a taxi driver with a customer have been replaced by the AI contained in phone apps, other tasks such as building maintenance, construction, and manufacturing will continue to require human participation. All of these areas are significant to the real estate business in particular. These discrepancies in drivers of automation versus job growth, significantly impact the theories that underpin future predictions in employment (Arntz, 2017; DeCanio, 2016). By contrast, the literature as a whole identifies variables such as hand precision and human to human contact as areas that will continue to be decisive for human employment. These tasks cover front line health care and surgery, hair cutting, cultural production and the arts. Furthermore, areas with soft skills like creative and social intelligence will be the types of non-routine tasks that cannot be replaced (Frey and Osborne, 2017).

There are a number of considerations regarding automation and gender. Dengler and Matthes (2015) demonstrate that male dominated vocations will be significantly more impacted than conventionally female jobs; however, it does not follow that the demand will increase for women because of this shift given that gender roles have determined both career choices, but also the social value placed on certain areas of work. A study of Pricewaterhouse Coopers LLP (PricewaterhouseCoopers LLP, 2017) reveals similar findings, stating that female workers could be more affected by automation in the short term, but male jobs are more at risk of being automated in the long term. Males have dominated areas like manufacturing and facility related production occupations, and these are among the highest in terms of substitution potential (Dengler and Matthes, 2015). There is a limitation of looking at the change in supply and demand terms, given that there are considerations about how value is determined, and where women's work has been subject to the devaluing caused by patriarchy. This raises the important issue about how a job is evaluated and how consistent the automation design systems are when they are broken down into specific tasks (Arntz et al., 2016).

In the existing literature, there is a wide range of the effects of NT on employment numbers. At the high end of the predicted numbers are studies like Bowles (2014) who predict a loss of 60 percent of jobs due to NT and the Frey and Osborne study (Frey and Osborne, 2013, 2017), cited over 3,500 times, that predicts that by 203047 percent of analyzed 730 
occupations will disappear through automation. By contrast, on the low end of the scale, Arntz et al. (2017) take a different approach by measuring automated tasks against full occupations, predict that only 9 percent to 11 percent of all jobs in OECD countries will be lost. To demonstrate the importance of tasks as opposed to isolating the automation of whole occupations, Arntz et al. (2017) use the data for the Frey and Osborne (2013) study that concluded that 47 percent of all jobs will be lost and reduced it to 9 percent by isolating the tasks within the jobs rather than the jobs themselves. The occupations defined by the substitution potential based on five tasks that include: manual non-routine tasks, interactive non-routine tasks, manual routine tasks, cognitive routine tasks and analytical non-routine task (Dengler and Matthes, 2015). Another international comparison is carried out by Nedelkoska and Quintini (2018). According to this, 14 percent of all jobs in OECD countries can be highly automated. For all 32 OECD countries analyzed in the study, this means 66 million jobs. Looking at the automation potential from 50 to 70 percent, it is even 32 percent of all jobs. This shows that structural changes are to be expected in large areas of the world of work as a result of digitization.

A study of the McKinsey Global Institute (McKinsey Global Institute, 2017) emphasizes on the job creation aspect of digitization. While NT's do replace jobs, they are creating new work possibilities. Accordingly, one-third of the newly emerged jobs of the past 25 years in the United States are directly linked to NT's, i.e. IT management and app creation. The study further underlines the importance of NT's on economies and their productivity.

The literature review presented has emphasized that the cross relational data and structural elements that has be used to describe the general trends within employment and automation can be applied to the real estate industry. What is unique to real estate, are the sub specialty areas like an emerging online and platform-based services that are already disrupting the real estate business as it has been conventionally run.

\section{Methodology and results}

Previous research has shown that it is not entire professions that can be automated, but rather tasks within occupations. In the following, the substitutability potential of occupations within the real estate industry in Germany is examined. The substitutability potential of an occupation is defined via the proportion of routine activities, which are likely to be automated by current technological capabilities (Dengler and Matthes, 2015).

When assessing the level of substitutability potential, the categorization suggested by Frey and Osborne (2013) is used: A low substitutability potential exists if a maximum of 30 percent of activities within an occupation can be performed by computers. An average substitutability potential means that between 30 percent and a maximum of 70 percent of activities are automatable. A high substitutability potential means that more than 70 percent of activities could be replaced by digitization.

The methodology applied in this contribution is set out in Figure 1.

In contrast to the previous studies on the impacts of automation on jobs, the substitution probabilities are not determined on the basis of American occupation data, but rather information on occupational research from the expert database BERUFENET (Bundesagentur für Arbeit, 2019), which provides information on all occupations known in Germany online and free of charge. The BERUFENET is used for job placement and information and contains approximately 3,900 occupations. The information provided includes information on the respective professional activities, necessary training or legal regulations.

Dengler and Matthes (2015) originally determined the task composition for each occupation on the basis of this database. For this purpose, the authors created a requirements matrix, in which approximately 8,000 requirements are assigned to the respective occupations. When deciding whether a work requirement should be understood as a routine or non-routine activity, it was explicitly researched whether the respective activity could be carried out by
Digitization and German real estate jobs 


\section{JPIF \\ 39,2}

\section{2}

Figure 1.

Methodology for the calculations of the automation

probabilities

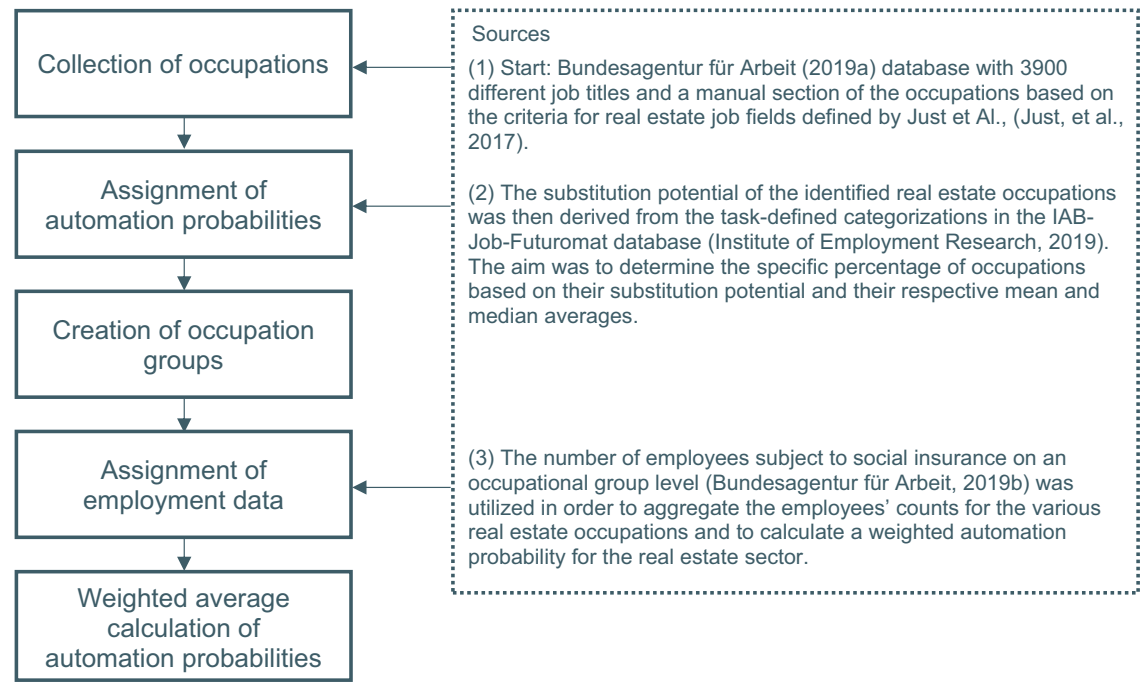

Source(s): Own representation

computer-controlled machines. Replicability by computers or computer-controlled machines was therefore a central criterion in deciding whether a requirement was categorized as a routine or non-routine activity. Therefore, the proportion of routine activities represent as a measure of the substitutability of these professions. Dengler and Matthes (2015) utilized the requirements matrix and calculated the proportion of routine activities (vs. non-routine activities) by dividing the core requirements in each individual occupation. These shares at individual occupational level are aggregated for the various occupational aggregates with a weight calculated on the basis of the number of employees in 2016 .

The requirements matrix is not publicly accessible, however, Dengler and Matthes created the database IAB-Job-Futuromat (Institute of Employment Research, 2019) for the public in order to access the calculated automation probabilities for each occupation. The IAB-JobFuturomat is a database that contains the occupation-specific substitution potentials along with job specific individual substitution potentials. Furthermore, the IAB-Job-Futuromat provides the substitution potentials for each of the 286 occupations taken from the second data set used in this study. The second data set is the BERUFENET database (Bundesagentur für Arbeit, 2019) which provides occupational titles from which 286 real estate sector occupation titles have been manually collected. These real estate titles have been categorized according to the classification of real estate industry job fields provided by Just et al. (2017). It is important to note that real estate can be either defined in a narrow sense or in a broad sense. The real estate sector within a narrow sense consists of the areas 1) real estate trade, 2) renting and leasing and 3) mediation and administration. However, far more activities are frequently also seen as been an essential part of the real estate sector. Consequently, Just et al. (2017) add additional areas to the real estate sector in a broad sense: 4) architectural/engineering offices, 5) construction industry (building construction/civil engineering), 6) real estate financers, 7) investment companies, 8) industrial cleaning and 9) other service providers. Some people argue that the planning of building should be seen as an integral aspect of real estate and thus, Architectural/engineering offices should be part of the real estate sector in a narrow sense. Other people might see the construction industry (building construction/civil engineering) as a core aspect of real estate, since the building of 
the properties is the most decisive aspect of the changing urban landscape. The decisive aspects of development and equity investment for the real estate sector are covered through the category investment companies. Consequently, we use the broad sense of the real estate sector for the categorization of real estate industry job fields to be able to examine the impacts of digitization on real estate sector jobs.

In the next step the IAB-Job-Futuromat database (Institute of Employment Research, 2019) was used to assign a substitutability probability to each occupation title (KldB 20105 digit level). Based on the approach by Dengler and Matthes (2015) each substitutability potential was mapped to the respective occupation title. For example, the job-profile of a facility manager contains the following essential activities. Therefore, the substitution probability of a facility manager is 60 percent (Table I).

These substitution probabilities at individual occupational level are aggregated for the various occupational groups with a weight calculated on the basis of the number of employees in 2018.

This requires a weighted average calculation of the substitutability potential and the respective employee count subject to social insurance. However, the employee count data is only available at occupational group level. In order to map the broadest possible occupational spectrum on the one hand, but on the other remain clear to a certain extent, the employee counts within an occupational group is assumed to be equally distributed following the approach by Dengler and Matthes (2015), which enables to calculate a weight based on the average substitutability of occupation titles within an occupational group and the employee count of the occupational group. Based on this approach the 286 occupation titles within 164 occupational groups have been aggregated covering a total of 5,231,766 employees subject to social insurance within the real estate industry (as set out in Table II). For these 5,231,766 employees within the real estate industry the weighted substitutability potential comes to 47.41 percent. This means that almost a half of all jobs in the real estate sector tasks can be automated by current technical capabilities.

A further insight can be gained by looking at the consolidated automation potential (Table III).

In analogy to Dengler and Matthes (2018), the automation potentials are classified as high ( $>70$ percent), medium ( 50 percent to 70 percent) and low ( $<30$ percent). This categorization that almost 36 percent of all jobs within the real estate sector have a high automation potential. Approximately 15 percent of the occupations have a medium automation potential. Overall, the analysis shows that approximately half of all the jobs within the real estate industry have an automation potential that exceeds 50 percent.
Digitization and German real estate jobs

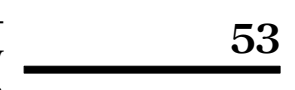


Table II.

Automation

Probability of the ten largest occupation groups

\begin{tabular}{|c|c|c|c|c|}
\hline & $\begin{array}{l}\text { Occupation group (English } \\
\text { name) }\end{array}$ & Occupation group (German name) & $\begin{array}{l}\text { Employee } \\
\text { count }\end{array}$ & $\begin{array}{l}\text { Averaged } \\
\text { automation } \\
\text { probability per } \\
\text { occupation group } \\
\text { (in \%) }\end{array}$ \\
\hline 1 & $\begin{array}{l}\text { Skilled workers in } \\
\text { commercial and technical } \\
\text { business administration } \\
\text { (without specialisation) }\end{array}$ & $\begin{array}{l}\text { Aufsichtskräfte im Aus- und } \\
\text { Trockenbau, Isolierung, Zimmerei, } \\
\text { Glaserei, Rollladen- und Jalousiebau }\end{array}$ & 936,387 & $44.00 \%$ \\
\hline 2 & $\begin{array}{l}\text { Specialists in building } \\
\text { services engineering } \\
\text { (without specialisation) }\end{array}$ & $\begin{array}{l}\text { Fachkräfte in der Gebäudetechnik } \\
\text { (ohne Spezialisierung) }\end{array}$ & 233,272 & $66.00 \%$ \\
\hline 3 & $\begin{array}{l}\text { Specialists in construction } \\
\text { electrics }\end{array}$ & Fachkräfte in der Bauelektrik & 224,334 & $75.00 \%$ \\
\hline 4 & $\begin{array}{l}\text { Specialists in metal } \\
\text { construction }\end{array}$ & Fachkräfte im Metallbau & 216,635 & $85.00 \%$ \\
\hline 5 & $\begin{array}{l}\text { Specialists in sanitary, } \\
\text { heating and air-conditioning } \\
\text { technology }\end{array}$ & $\begin{array}{l}\text { Fachkräfte in der Sanitär-, Heizungs- } \\
\text { und Klimatechnik }\end{array}$ & 171,535 & $70.00 \%$ \\
\hline 6 & $\begin{array}{l}\text { Specialists in woodworking, } \\
\text { furniture and interior design }\end{array}$ & $\begin{array}{l}\text { Fachkräfte im Holz-, Möbel- und } \\
\text { Innenausbau }\end{array}$ & 142,619 & $55.75 \%$ \\
\hline 7 & $\begin{array}{l}\text { Specialists in information } \\
\text { and telecommunications } \\
\text { technology }\end{array}$ & $\begin{array}{l}\text { Fachkräfte in der Informations- und } \\
\text { Telekommunikationstechnik }\end{array}$ & 141,812 & $94.33 \%$ \\
\hline 8 & $\begin{array}{l}\text { Specialists in electrical } \\
\text { operating technology }\end{array}$ & $\begin{array}{l}\text { Fachkräfte in der elektrischen } \\
\text { Betriebstechnik }\end{array}$ & 116,174 & $70.00 \%$ \\
\hline 9 & $\begin{array}{l}\text { Specialists for painting and } \\
\text { varnishing work }\end{array}$ & $\begin{array}{l}\text { Fachkräfte für Maler- und } \\
\text { Lackiererarbeiten }\end{array}$ & 113,616 & $30.25 \%$ \\
\hline 10 & $\begin{array}{l}\text { Technical draughtsmen and } \\
\text { women }\end{array}$ & Technische Zeichner/innen & 111,285 & $78.25 \%$ \\
\hline
\end{tabular}

Table III.

Summarized automation probabilities of jobs in the real estate sector

\begin{tabular}{lcc}
\hline & Number of jobs & Percentage of all jobs \\
\hline Probability of Automation of over $70 \%$ & $1,883,724$ & $36.01 \%$ \\
Probability of Automation between 50 and $70 \%$ & 783,423 & $14.97 \%$ \\
Sum: Probability of Automation of over $50 \%$ & $2,667,147$ & $50.98 \%$
\end{tabular}

Source(s): Bundesagentur für Arbeit (Bundesagentur für Arbeit, 2019a), Bundesagentur für Arbeit (Bundesagentur für Arbeit, 2019b), Institute of Employment Research (Institute of Employment Research, 2019); own calculations

\section{Conclusion}

The digital transformation of the real estate sector is lagging behind other sectors. However, the real estate industry is facing seismic change. The adaption of technologies such as data analytics, artificial intelligence, machine learning and robotics are transforming operations. Highly administrative, humanly performed tasks are becoming increasingly redundant. Although the disruption is significant, the industry has a number of limitations that make the complete automation of this sector difficult or impossible to completely make. By contrast, there are notable intersections of negative trends that are also a consideration and that is the deskilling of labor and the greater polarization between highly skilled or professional credentials and employment that can be achieved by anyone. When work can be done by the lowest common denominator, the over abundant supply means that the wages can remain 
low. The problem with low wages is two-fold in terms of stagnation, and it means that lower incomes mean that less money is circulating in the economy, and that has a secondary effect of reducing any capacity for reinvestment and then growth. The circular effect on real estate and the economy in general, is punctuated by a smaller pool of consumers for property and a lower overall price as well. The deskilling and polarizing of labor along with the economic stagnation that this causes, is countered by the benefits such as the creation of new industries and work opportunities. Further, there are a number of factors that will contribute to a lag for adopting NT's and the driverless car is a good example where the existing technology is available, but the legislative framework and social acceptance of lags behind. These social and political considerations are significant to the growth of automation and at the same time, they are difficult to predict and therefore create limitations on any model that assesses the risk to employment. Both the obstacles to a quick transformation and job creations thanks to the new possibilities of NT's highlight the necessary aspects that also have to be considered in the interpretation of the 47 percent figure of disappear jobs within the real estate industry. Further, an occupational approach that looks at macroeconomic trends along with standard data collected from current employment data can only represent a snap-shot of a static scenario analysis. This contribution has emphasized that a task-based approach demonstrates how high the percentage is of jobs affected: Almost every second job within the real estate industry. However, also in the real estate industry new jobs will be generated thanks due to NT. For example, in data analytics and photo capturing technologies, there has been a significant amount of benefits and growth for the real estate industry (Conway, 2018).

This contribution has focused on the derivation of an approximation for the magnitude of the job killer aspect of digitization. As set out, digitization has also the job motor aspect and many new jobs will arise thanks to digitization. Structural change can be painful for the affected industries, especially if the size of the change required is considerable. Consequently, the real estate industry should be aware of significant shifts and adjustment pains within the sector due to digitization.

\section{References}

Addo, K. (2016), Core Labor Standards and International Trade, Springer, Wiesbaden.

Arntz, M., Gregory, T. and Zierahn, U. (2017), "Revisiting the risk of automation”, Economics Letters, Vol. 159, pp. 157-160.

Arntz, M., Gregory, T. and Zierahn, U. (2016), The Risk of Automation for Jobs in OECD Countries, Organisation for Economic Co-operation and Development, Paris, Version: 189.

Bessen, J.E. (2016), "How computer automation affects occupations: technology, jobs and skills", Working Paper No. 15-49, Law and Economics Research Paper, Boston University School of Law.

Bonin, H., Gregory, T. and Zierahn, U. (2015), “Übertragung der Studie von Frey/Osborne (2013) auf Deutschland”, available at: ftp://ftp.zew.de/pub/zew-docs/gutachten/Kurzexpertise_BMAS_ ZEW2015.pdf (accessed 15 March 2019).

Bowles, J. (2014), "T Chart of the Week: $54 \%$ of EU jobs at risk of computerization", available at: http:// bruegel.org/2014/07/chart-of-the-week-54-of-eu-jobs-at-riskof-computerisation (accessed 24 April 2019).

Brzeski, C. and Burk, I. (2015), "Die Roboter kommen. Folgen der Automatisierung für den deutschen Arbeitsmarkt”, available at: https://www.ingdiba.de/pdf/ueber-uns/presse/publikationen/ingdiba-economic-research-die-roboterkommen.pdf (accessed 18 March 2019).

Bundesagentur für Arbeit (2019a), "BERUFENET database", Germany Agency for Employment, available at: www.berufenet.arbeitsargentur.de/ (accessed 11 March 2019).

Bundesagentur für Arbeit (2019b), "Die Entwicklung des Arbeits- und Ausbildungsmarktes", Germany Agency for Employment, available at: www.statistik.arbeitsagentur.de (accessed 18 April 2019). 
JPIF

39,2

Conway, J.J.E. (2018), Artificial Intelligence and Machine Learning: Current Applications in Real Estate, Massachusetts Institute of Technology.

DeCanio, S.J. (2016), "Robots and humans-complements or substitutes?", Journal of Macroeconomics, Vol. 49, pp. 280-291.

Deloitte (2018), "Daten sind das neue Gold: Immobiliendienstleistung 2030 - technological changes in the real estate industry and the effects on employees", available at: https://www2.deloitte.com/ content/dam/Deloitte/dk/Documents/real-estate/Downloads/02_Data \%20is $\% 20$ the $\% 20$ new $\% 20$ gold_Print \%20version.pdf (accessed 29 April 2019).

Dengler, K. and Matthes, B. (2018), "The impacts of digital transformation on the labor market: substitution potentials of occupations in Germany", Technological Forecasting and Social Change, Vol. 137, pp. 304-316.

Dengler, K. and Matthes, B. (2016), "Auswirkungen der Digitalisierung auf die Arbeitswelt: Substituierbarkeitspotenziale nach Geschlecht”, available at: http://doku.iab.de/aktuell/2016/ aktueller_bericht_1624.pdf (accessed 28 March 2019).

Dengler, K. and Matthes, B. (2015), "Folgen der Digitalisierung für die Arbeitswelt: Substituierbarkeitspotenziale von Berufen in Deutschland", available at: http://doku.iab.de/ forschungsbericht/2015/fb1115.pdf (accessed 28 March 2019).

Frey, C.B. and Osborne, M.A. (2013), "The future of employment: how susceptible are jobs to computerisation?”, Working Paper, University of Oxford.

Frey, C.B. and Osborne, M.A. (2017), "The future of employment: how susceptible are jobs to computerisation?", Technological Forecasting and Social Change, Vol. 114, pp. 254-280.

Gregory, T., Salomons, A. and Zierahn, U. (2016), "Racing with or against the machine? Evidence from Europe”, Working Paper, ZEW-Centre for European Economic Research, No. 16-053, Mannheim.

Institute of Employment Research (2019), "IAB-job-futuromat", German Institute of Employment Research, available at: www.job-futuromatiab.de (accessed 17 March 2019).

Just, T., Voigtländer, M., Eisfeld, R., Henger, R., Hesse, M. and Toschka, A. (2017), "Wirtschaftsfaktor Immobilien 2017”, IRE|BS International Real Estate Business School, Universität Regensburg, available at: https://epub.uni-regensburg.de/36042/ (accessed 11 March 2019).

Makridakis, S. (2017), "The forthcoming Artificial Intelligence (AI) revolution: its impact on society and firms", Futures, Vol. 90, pp. 46-60.

McKinsey Global Institute (2017), "Technology, jobs and the future of work - global impacts of automation on the world of work", available at: https://www.mckinsey.com/ /media/McKinsey/ Featured $\% 20$ Insights/Employment $\% 20$ and $\% 20$ Growth/Technology $\% 20$ jobs $\% 20$ and $\% 20$ the $\% 20$ future \%20of\%20work/MGI-Future-of-Work-Briefing-note-May-2017.ashx (accessed 22 April 2019).

Nedelkoska, L. and Quintini, G. (2018), “Automation, skills use and training”, Working Paper, OECD Social, Employment and Migration, No. 202, Paris.

Picketty, T. (2014), Capital in the 21st Century, Harvard University Press, Cambridge.

PricewaterhouseCoopers LLP (2017), "Will robots steal our jobs? - analysis of the impacts of automation on UK jobs, being potentially at risk by 2030", available at: https:/www.pwc.at/de/ publikationen/verschiedenes/impact-of-automation-on-jobs-2018.pdf (accessed 10 April 2019).

Thompson, D. (2015), “A world without work”, The Atlantic, Vol. 316 No. 1, pp. 50-56.

West, D.M. (2018), The Future of Work: Robots, AI, and Automation, Brookings Institution Press, Washington.

\section{Further reading}

O'Donnell, A. (2017), "When will traditional real estate catch up to the modern world? A professional services occupier view", Corporate Real Estate Journal, Vol. 6 No. 4, pp. 300-306.

\section{Corresponding author}

Daniel Piazolo can be contacted at: daniel.piazolo@wi.thm.de 


\section{Appendix}

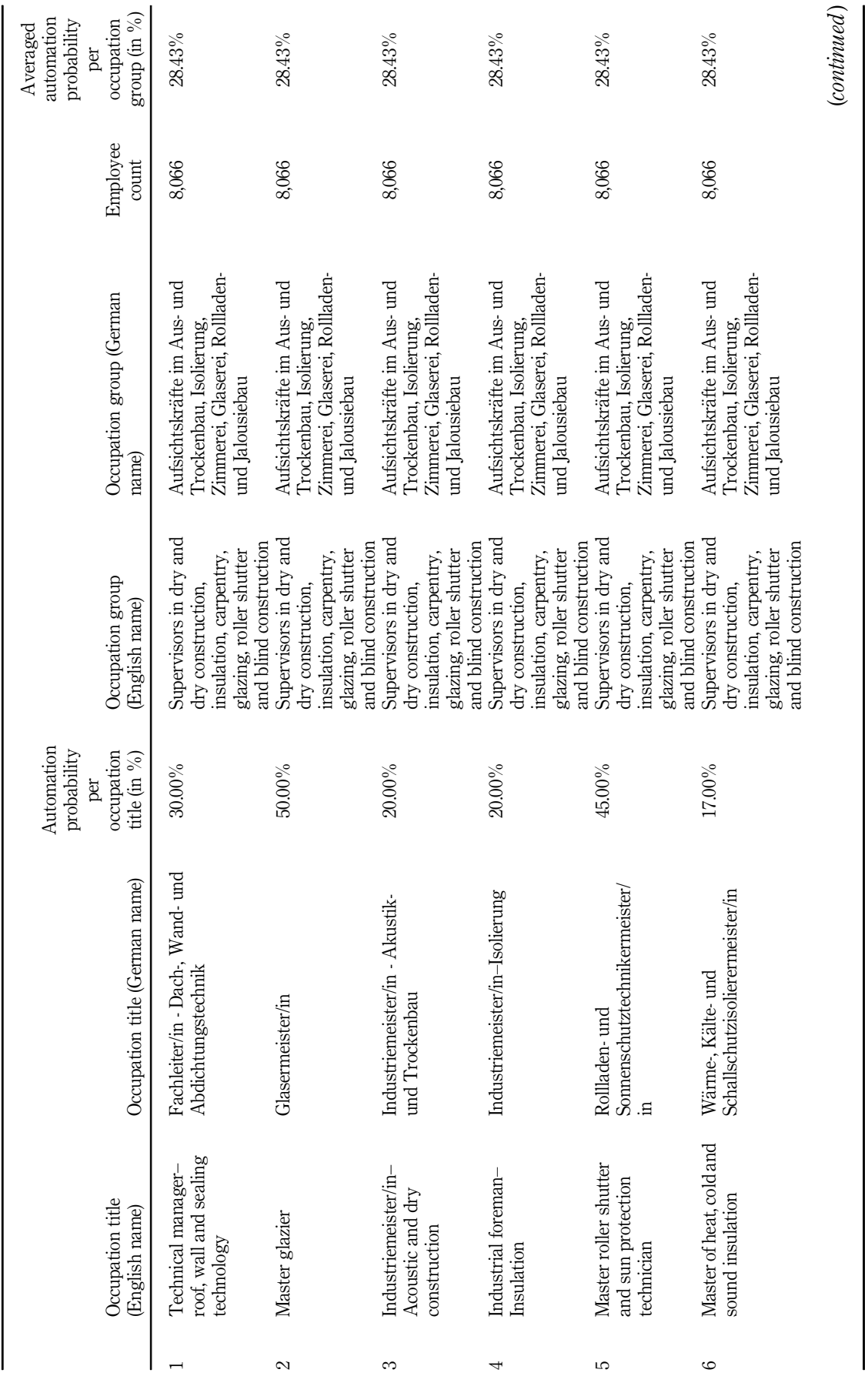

Digitization

and German real estate jobs

57
Table AI.

Automation

Probability per

Occupation Group 164

occupation groups

have been collected which consisted of 286 occupation titles. The mean value of the automation probability of an occupation group has been derived from the automation probabilities of the occupation titles it contains 
JPIF
39,2

\section{8}

\section{1}

WIII

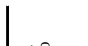

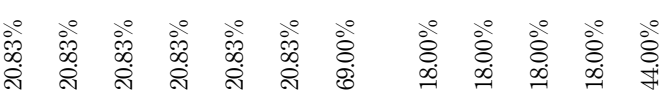

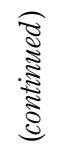

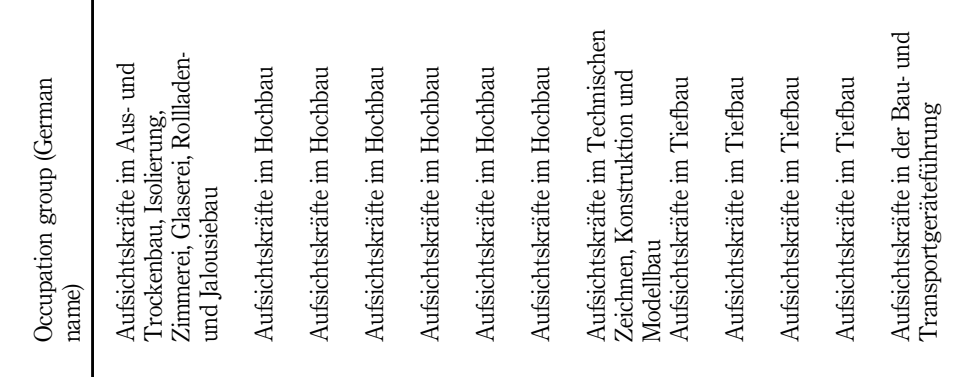

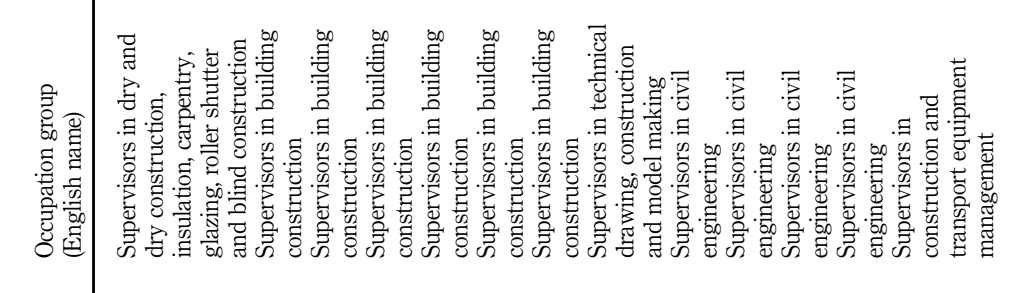

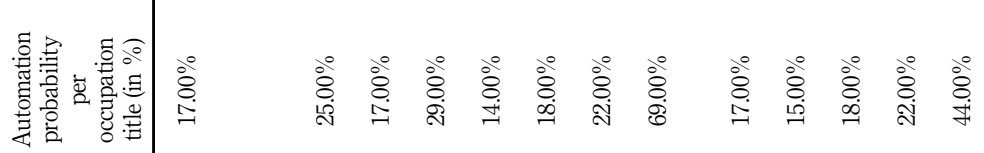

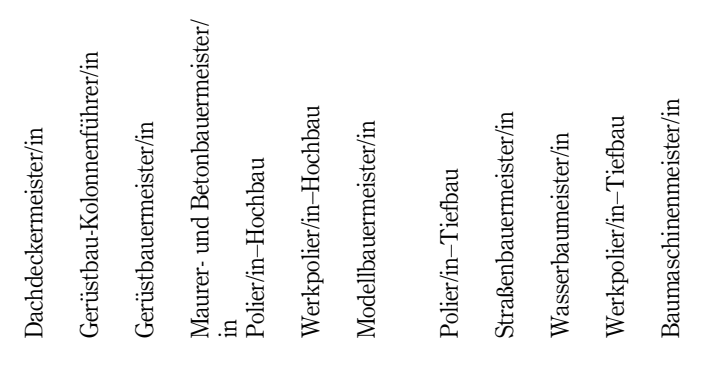

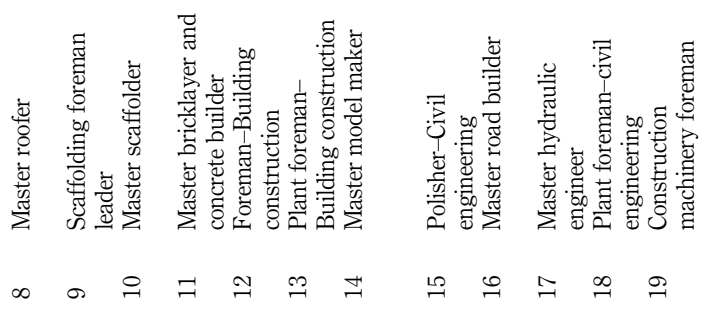

Table AI. 


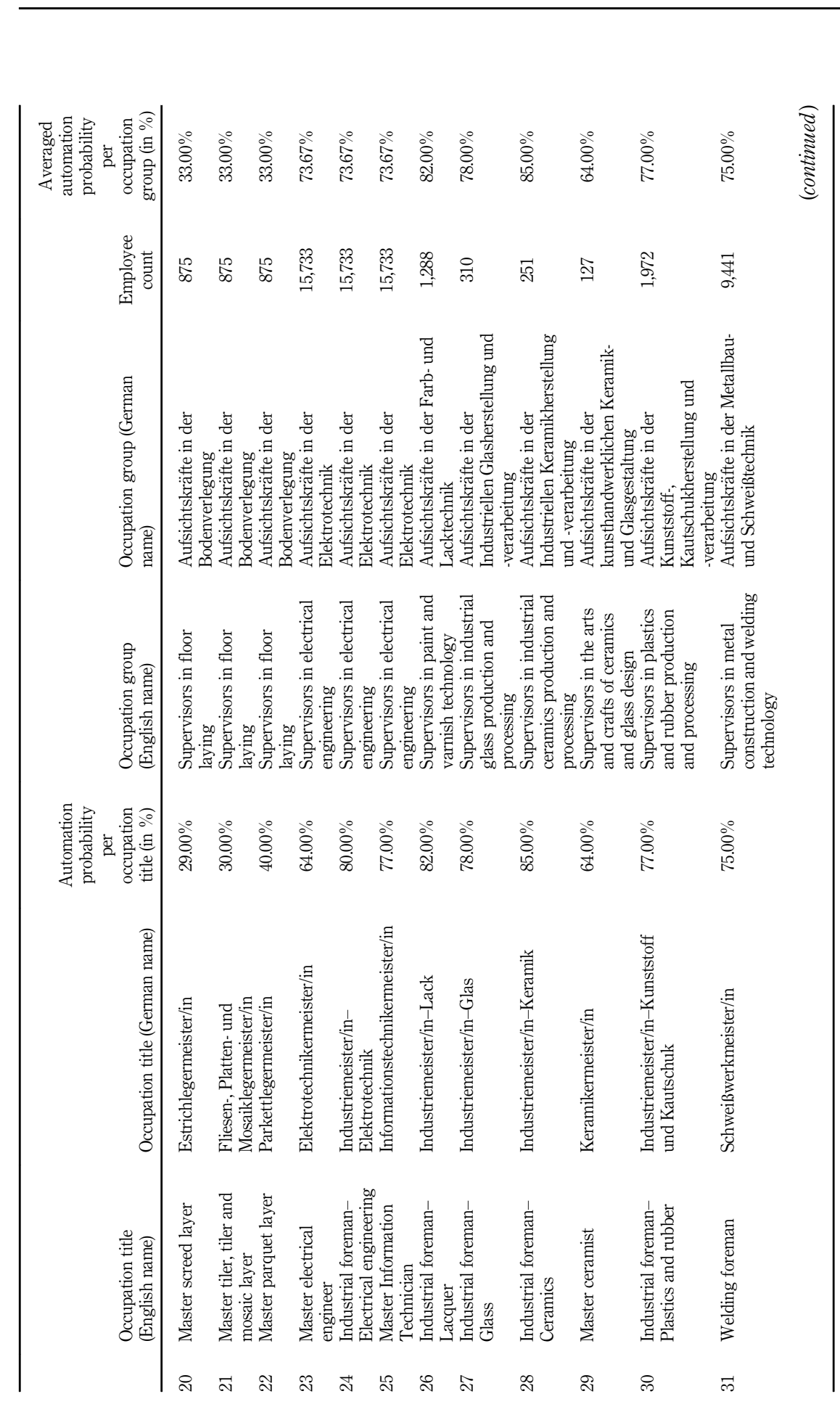

Digitization and German real estate jobs

59

Table AI. 


\section{JPIF \\ 39,2}

60

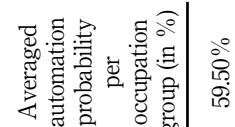

客

枣

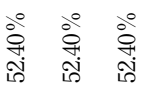

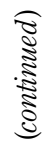

离苛

落

苦

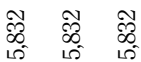

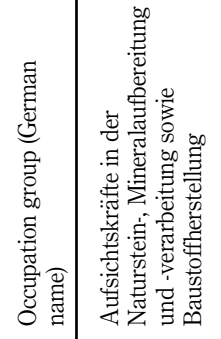

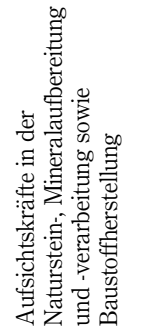

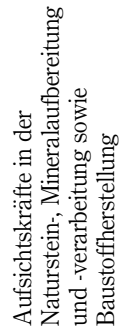

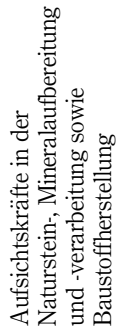

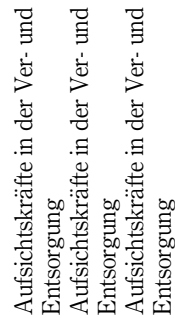

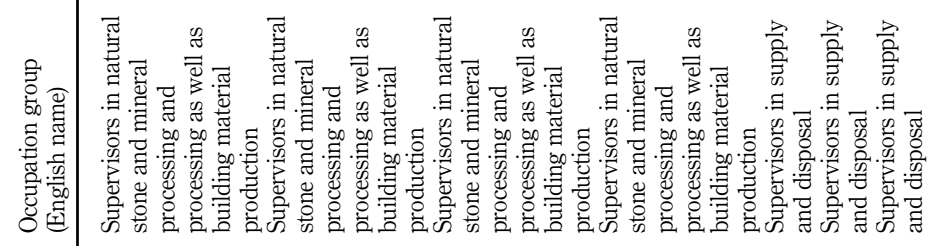

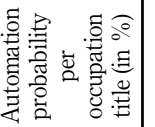

$\stackrel{8}{8}$

@े @े

Table AI.

$\stackrel{\circ}{\stackrel{8}{8}}$

$\stackrel{0}{8}$
8
0
10
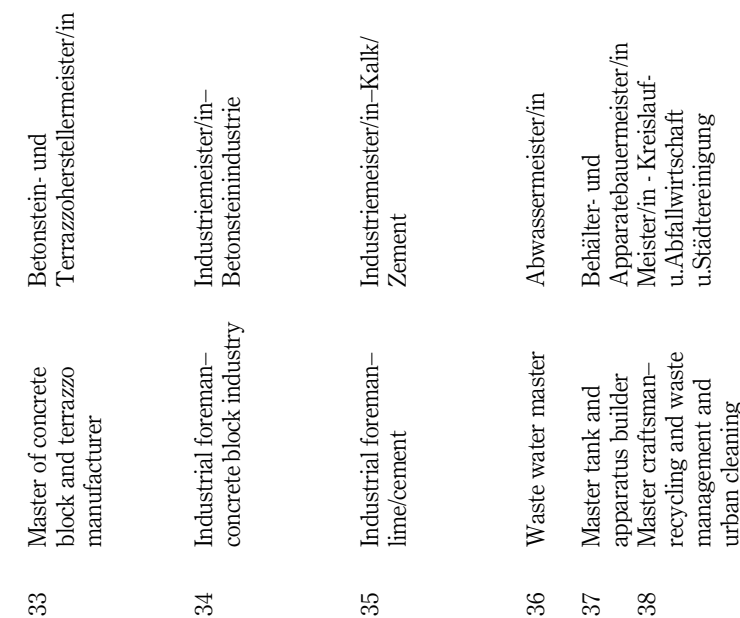


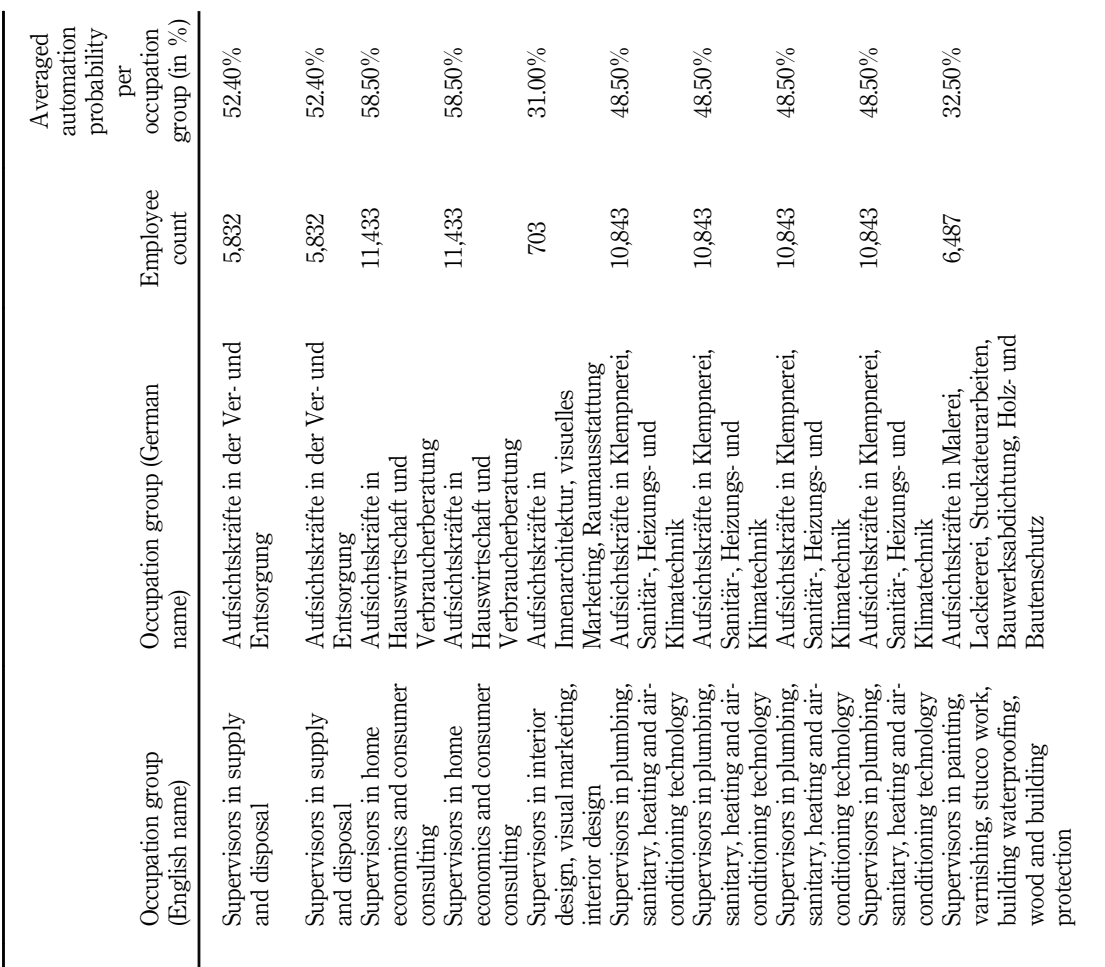

Digitization

and German

₹ real estate jobs

61

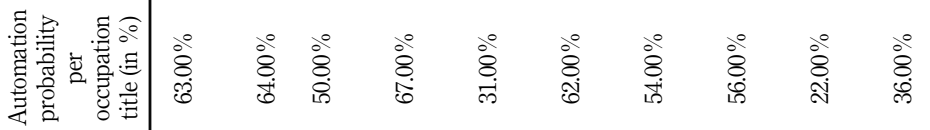

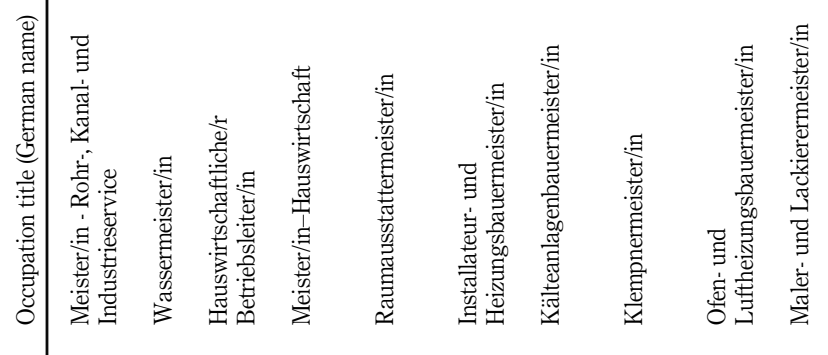

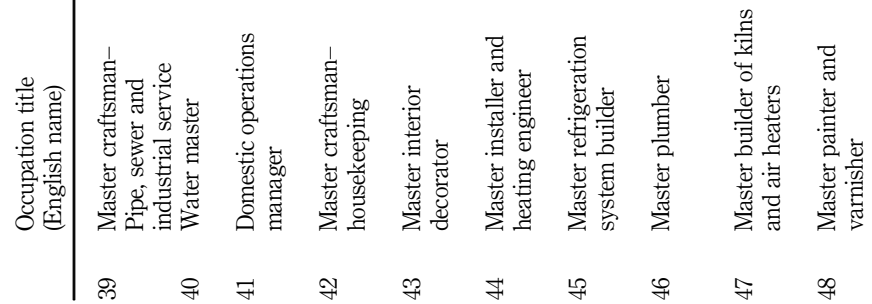

Table AI. 


\section{JPIF \\ 39,2}

62

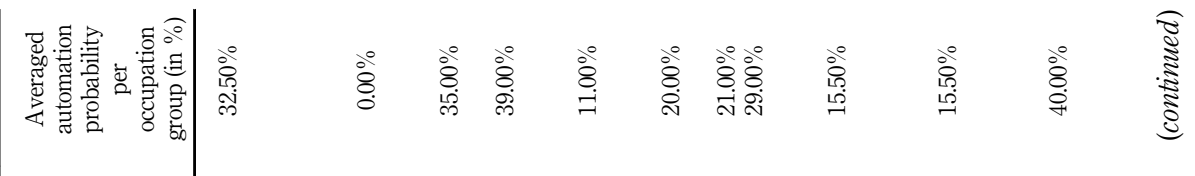

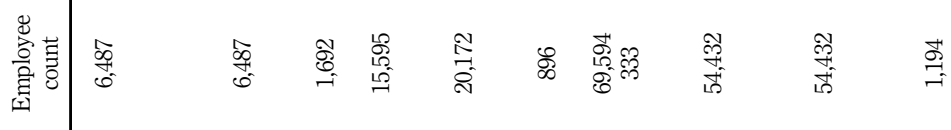

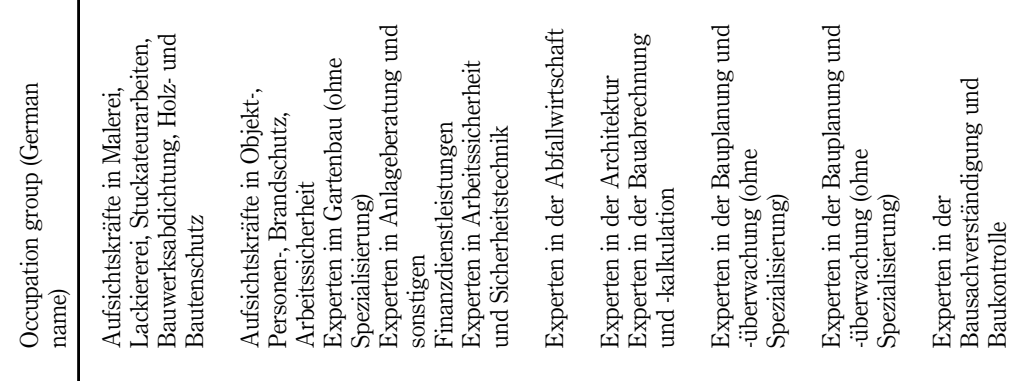

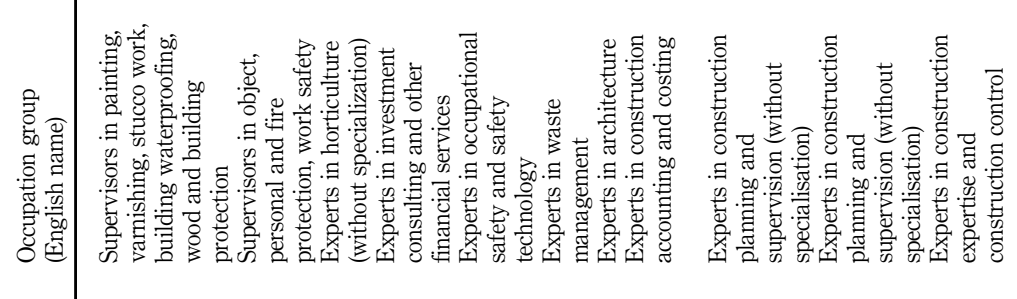

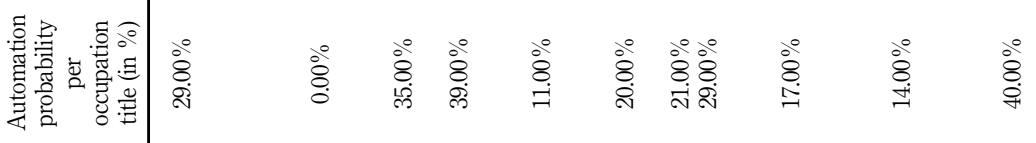

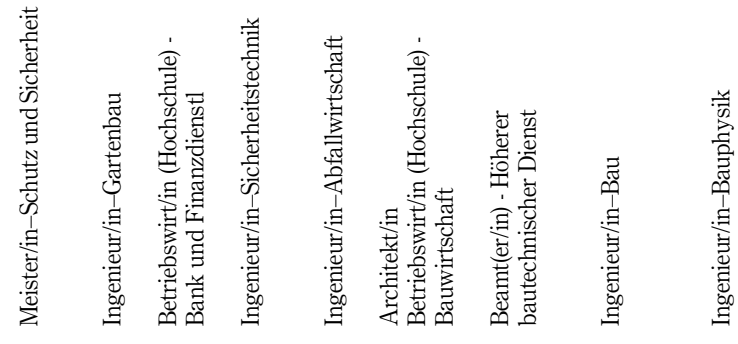

Table AI.

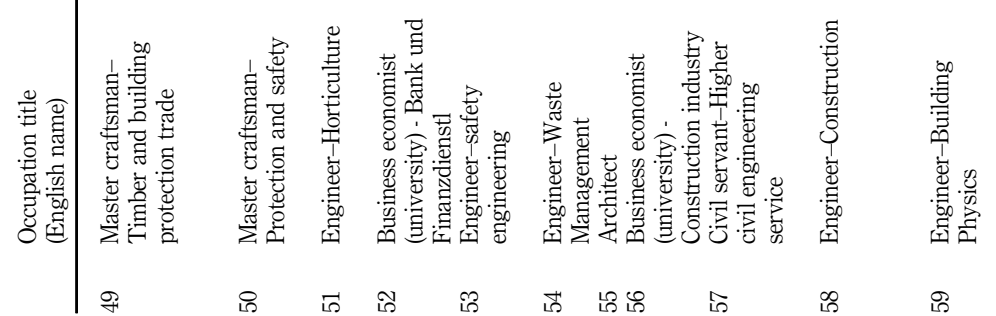




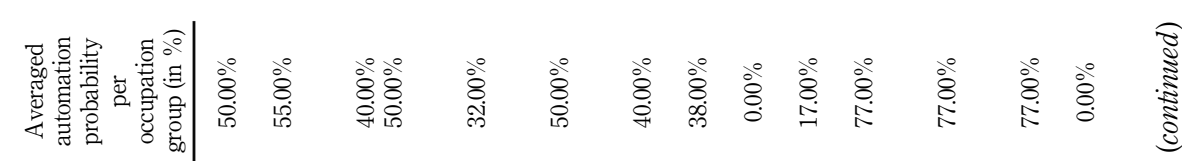

Digitization

and German

real estate jobs

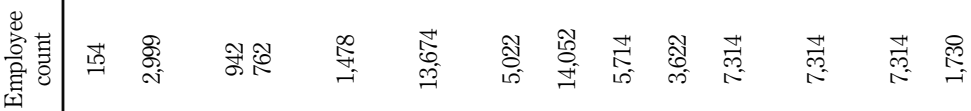

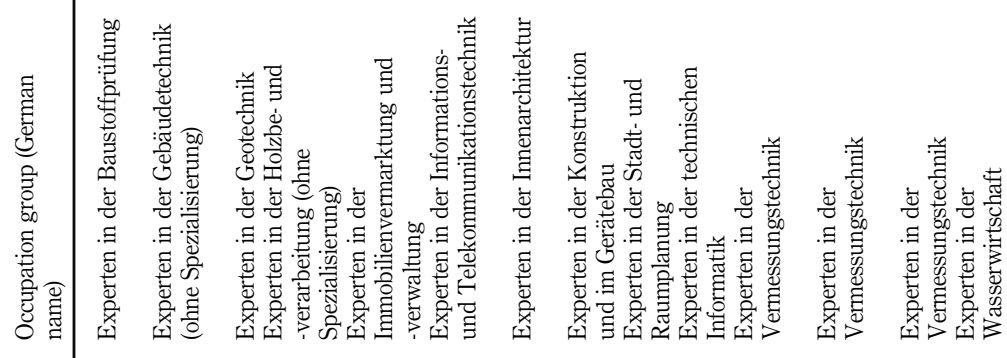

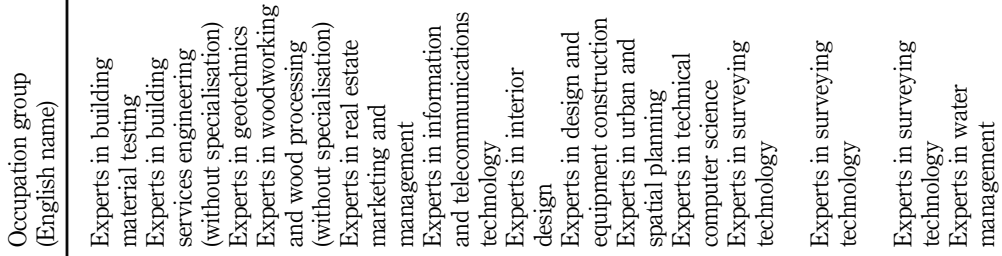

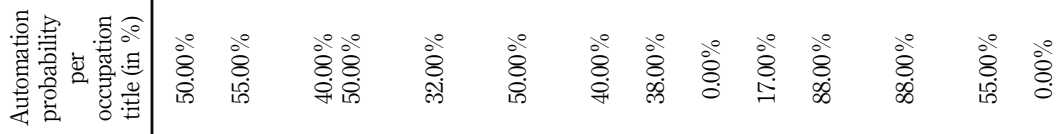

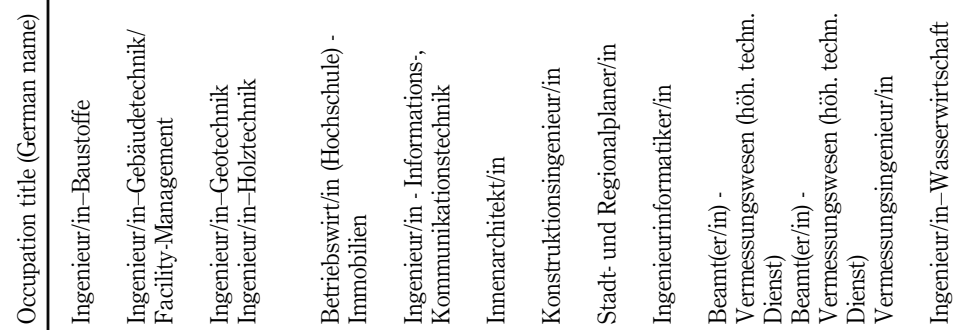

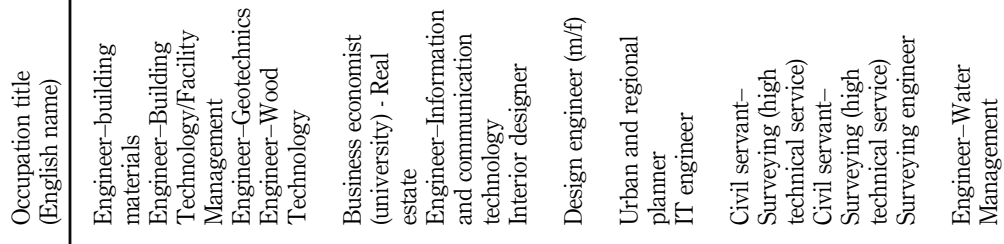

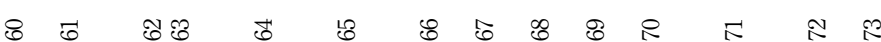

Table AI. 
JPIF
39,2

64

Table AI.

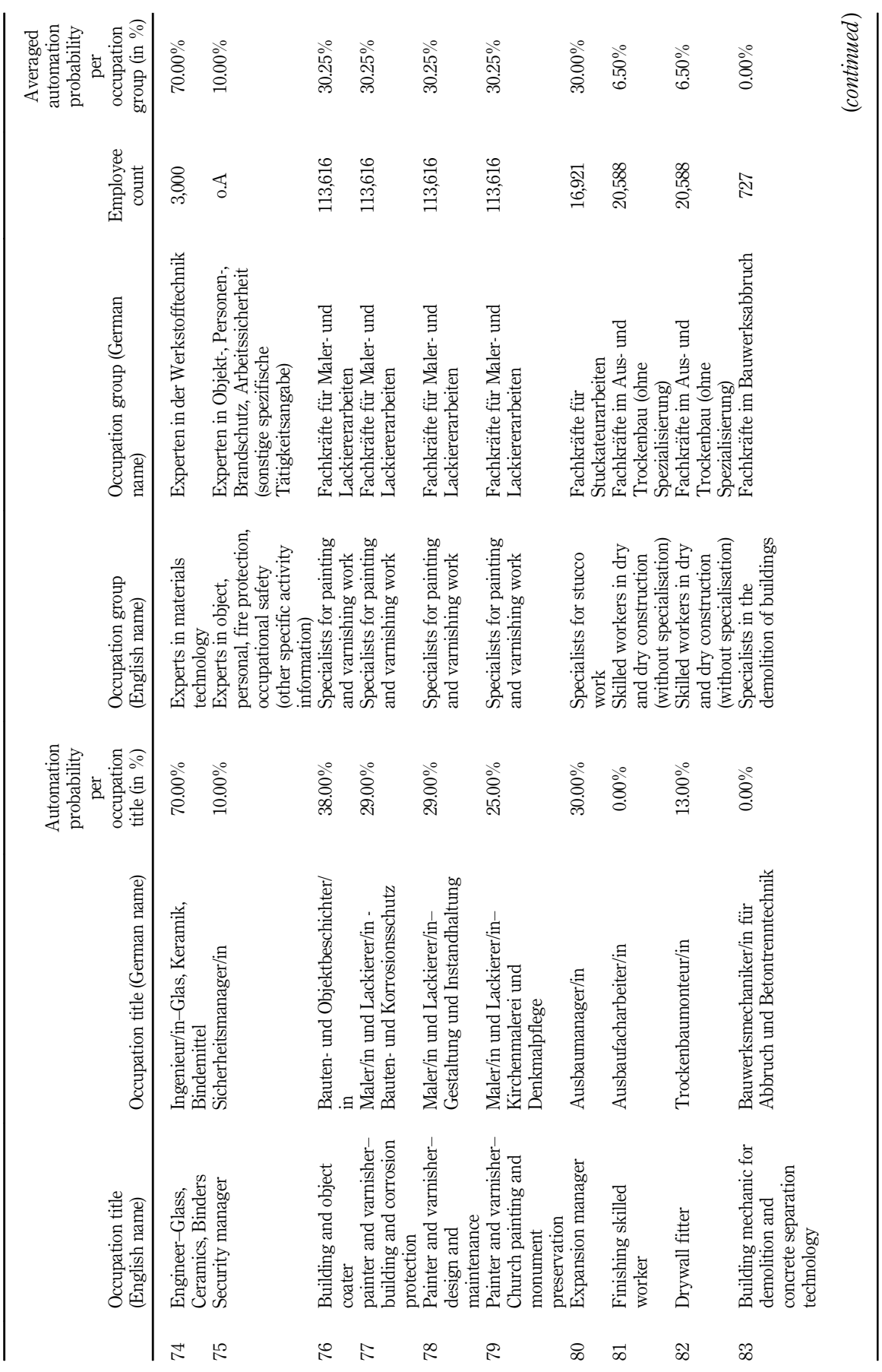




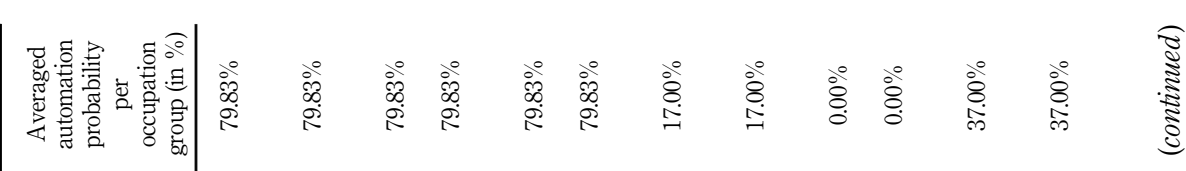

Digitization

and German

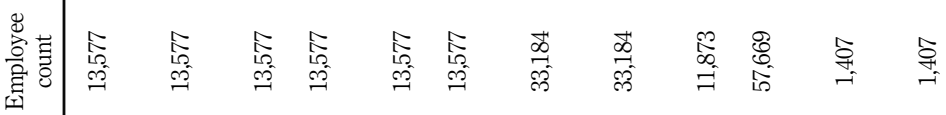
real estate jobs

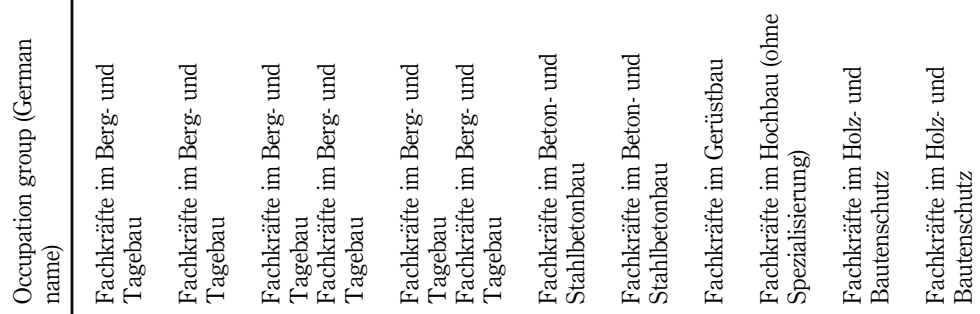

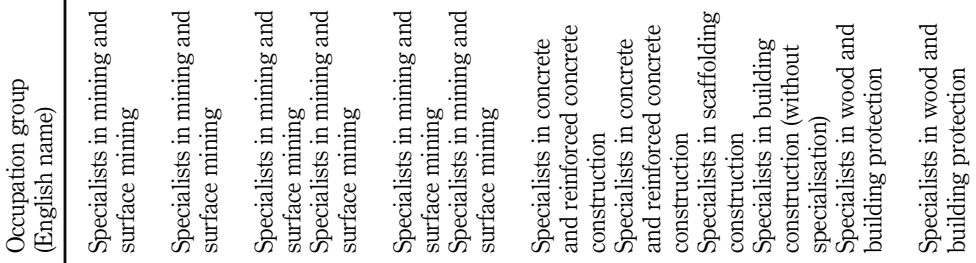

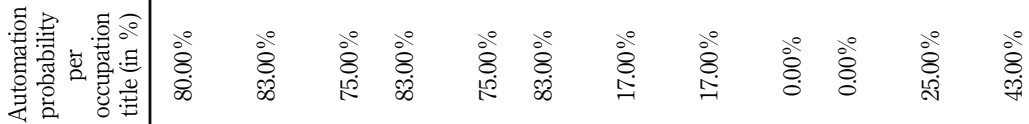

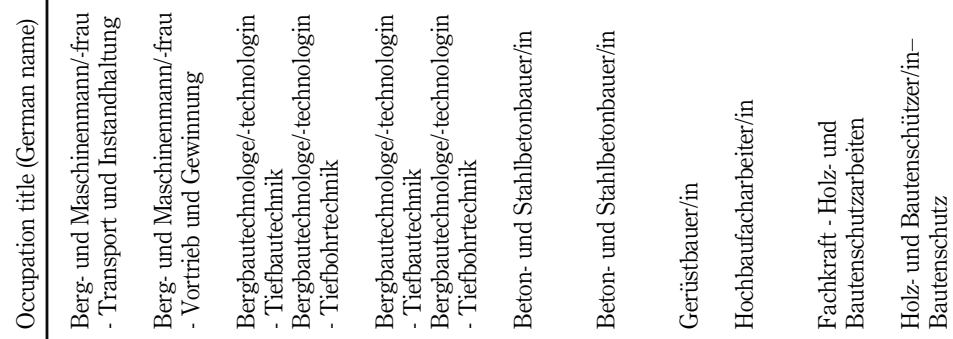

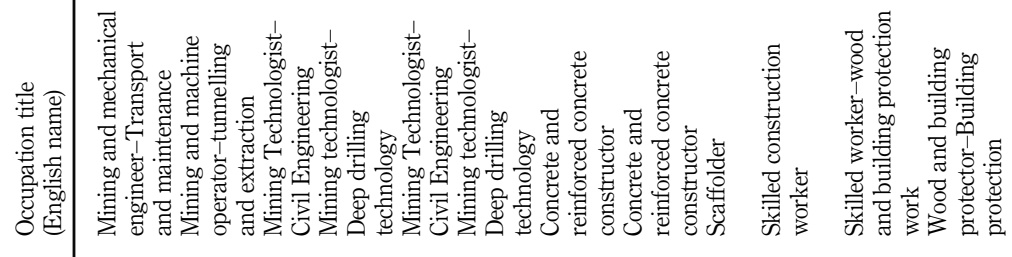

サ

Table AI. 


\section{JPIF \\ 39,2}

66

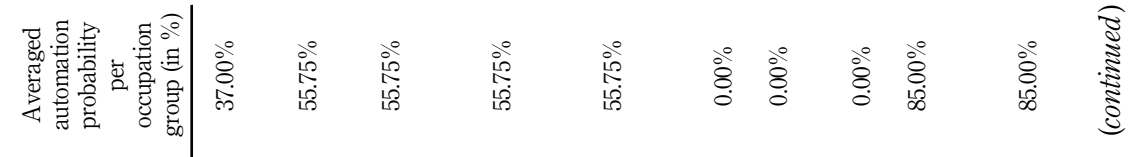

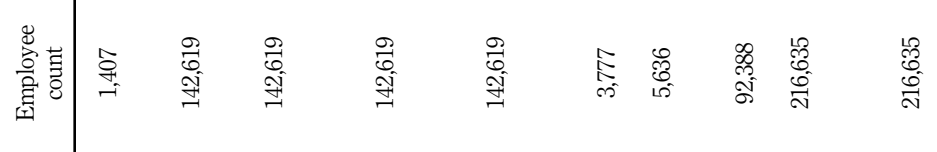

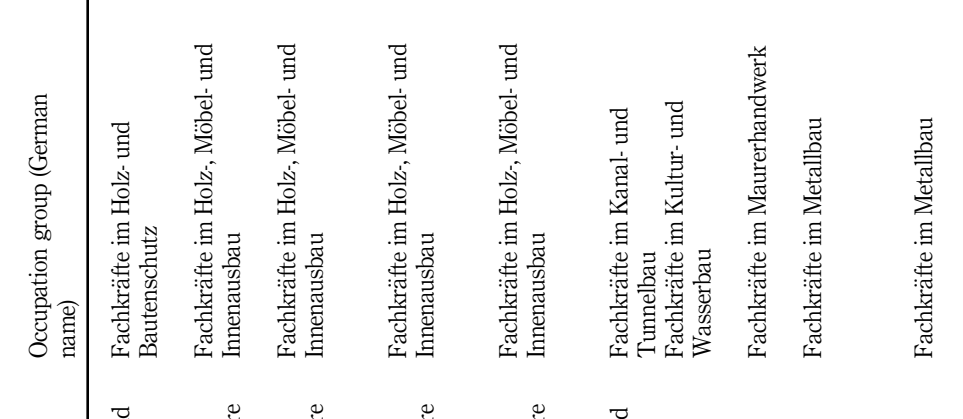

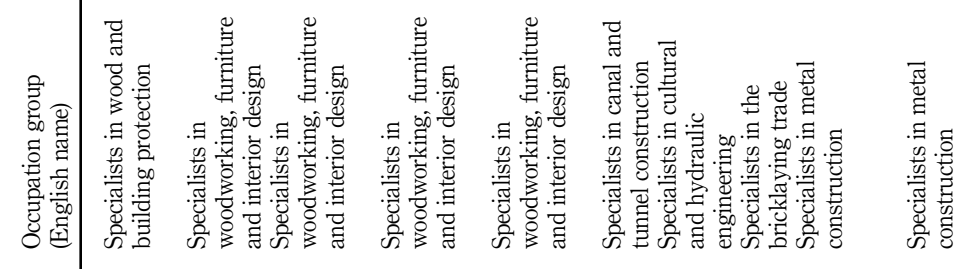

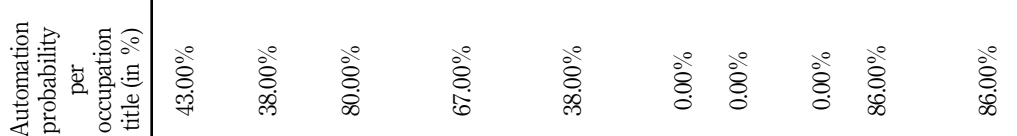

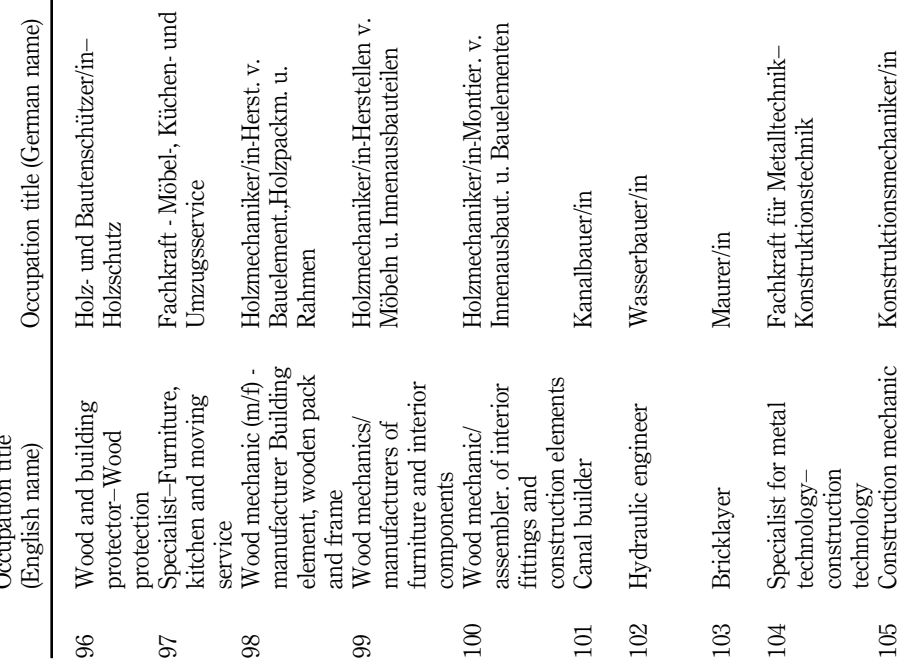

Table AI. 


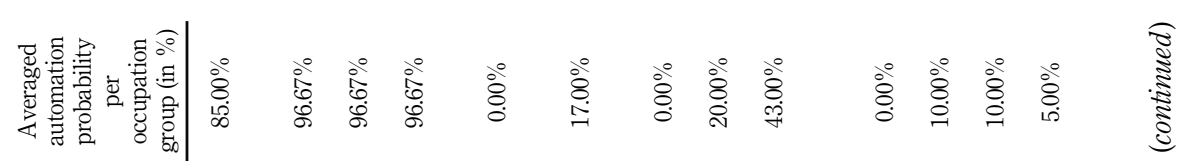

Digitization

and German

real estate jobs

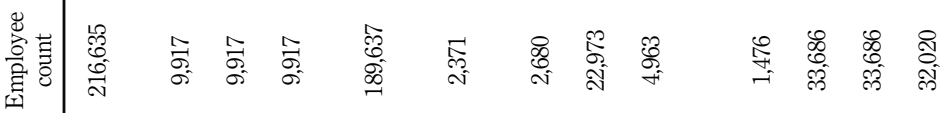

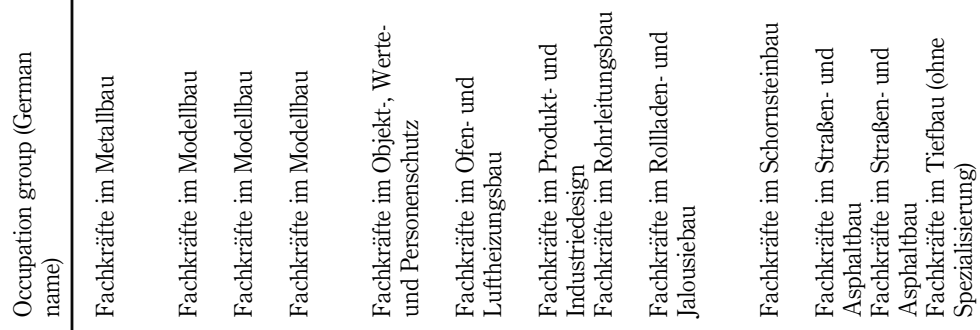

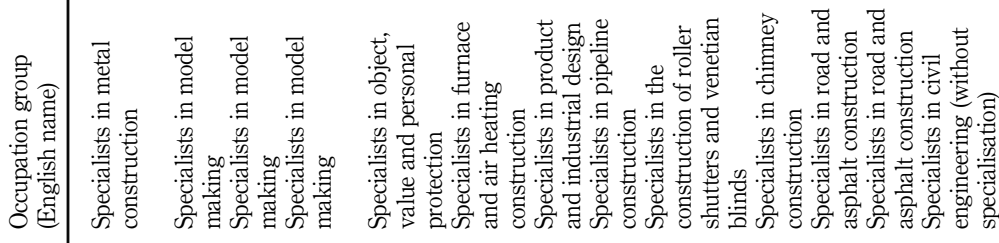

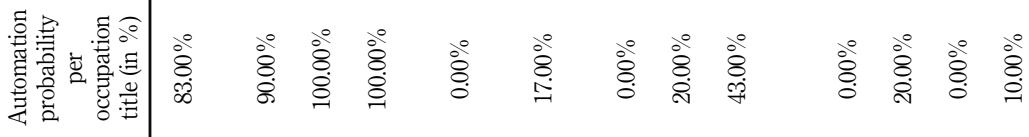

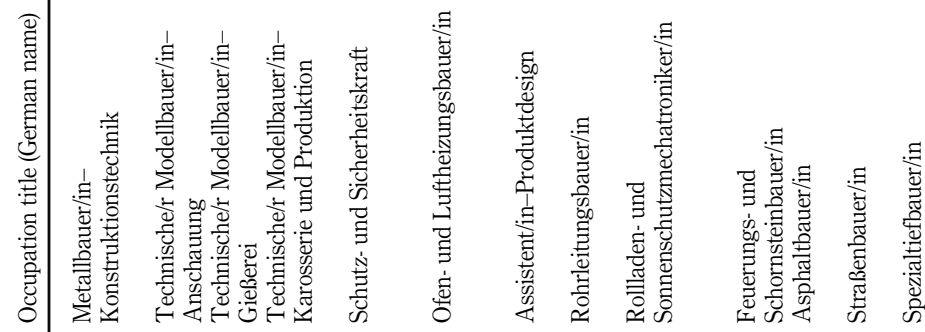

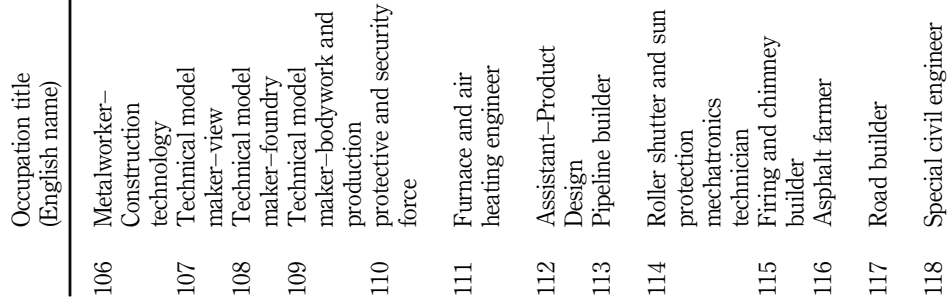

Table AI. 


\section{JPIF \\ 39,2}

68

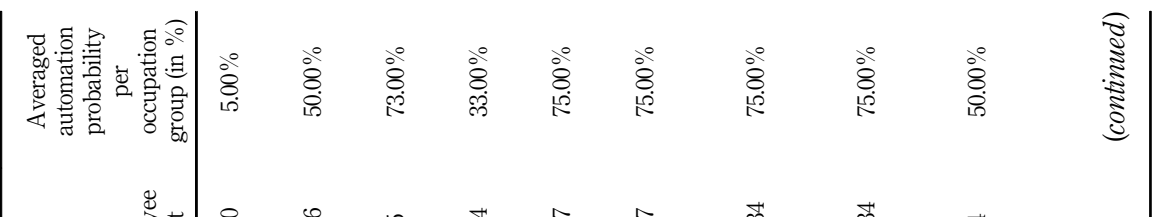

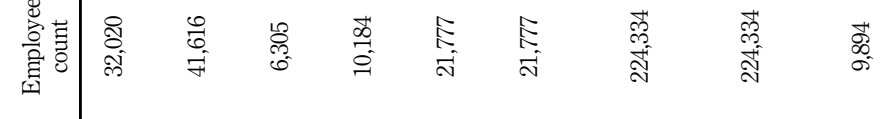

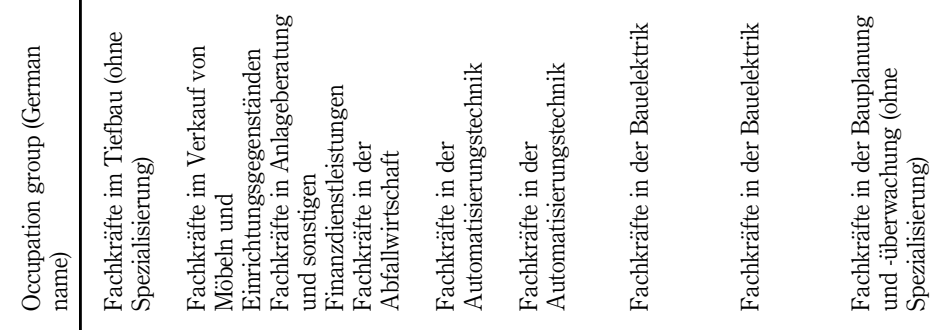

IIIIIIIIII

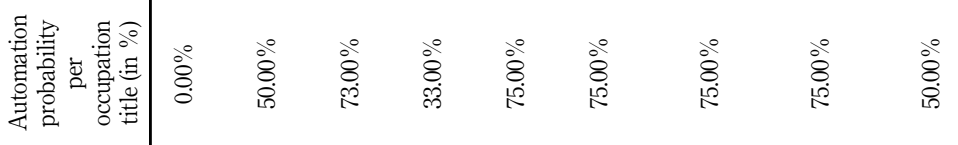

Table AI.

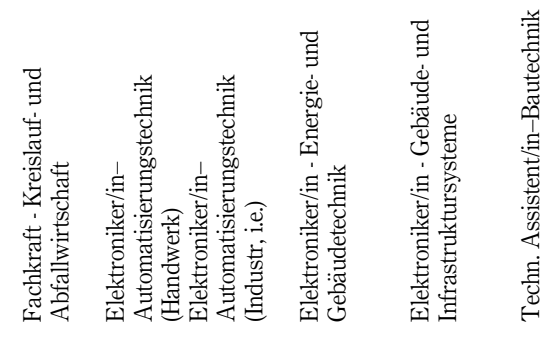

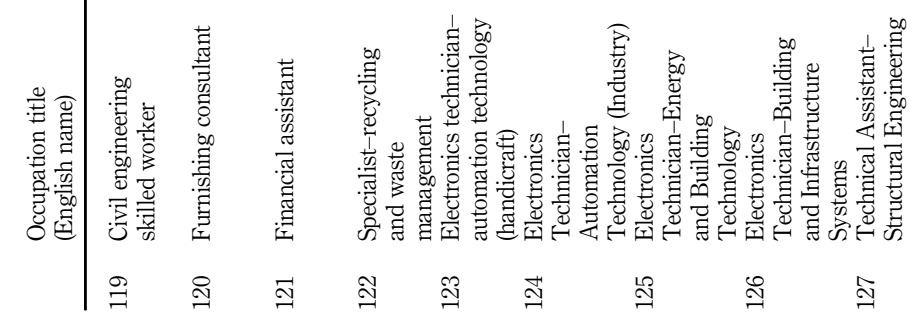




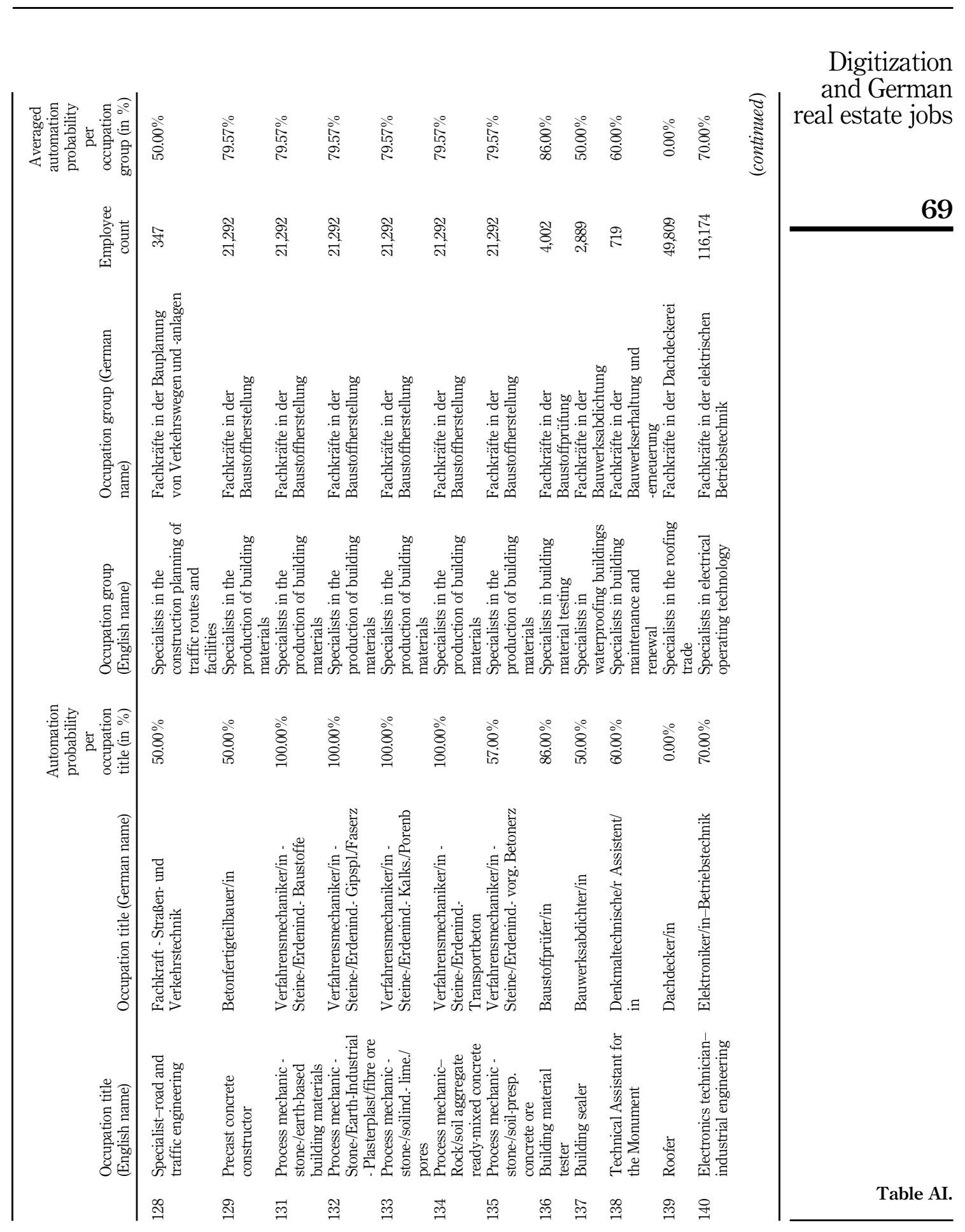


JPIF
39,2

70

Table AI.

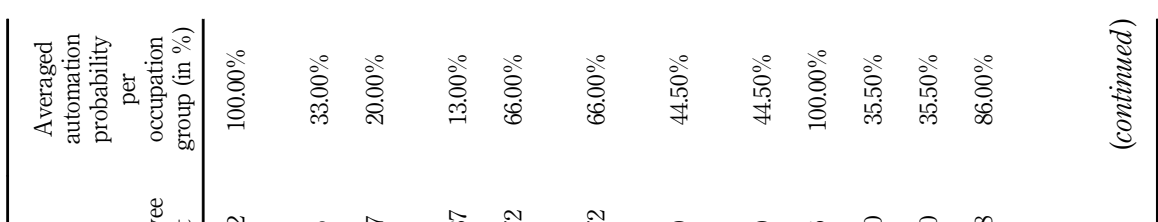

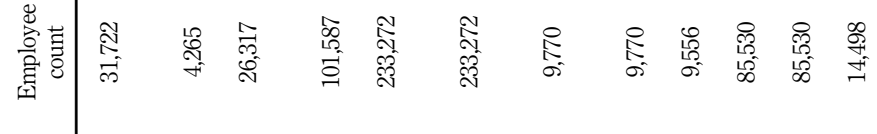

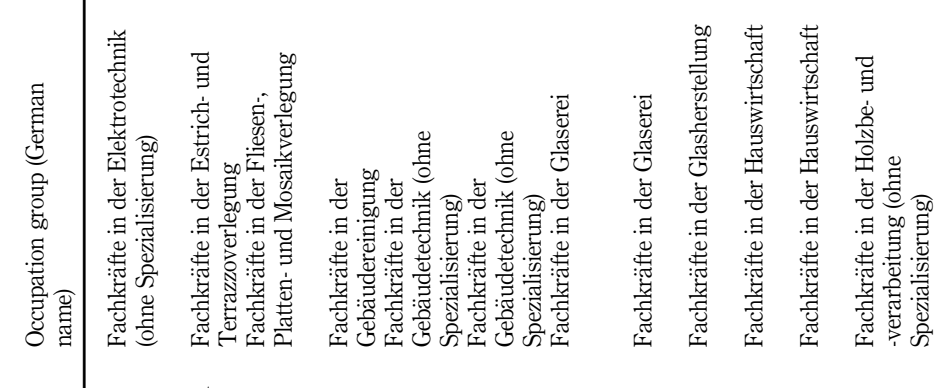

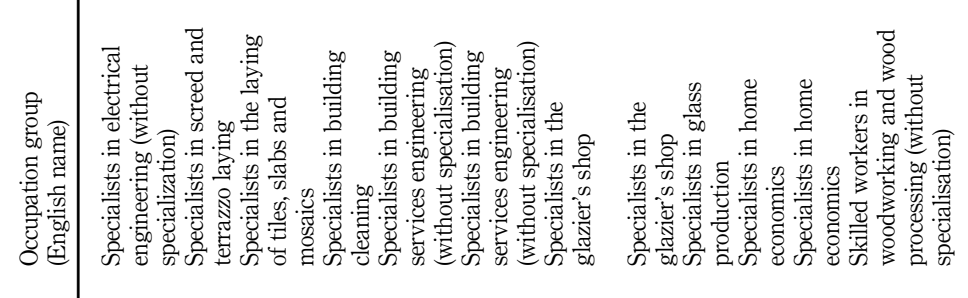

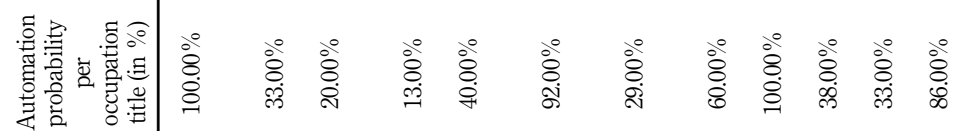

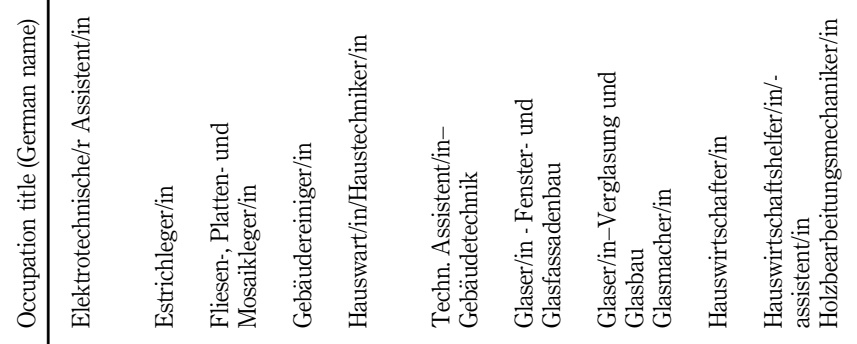

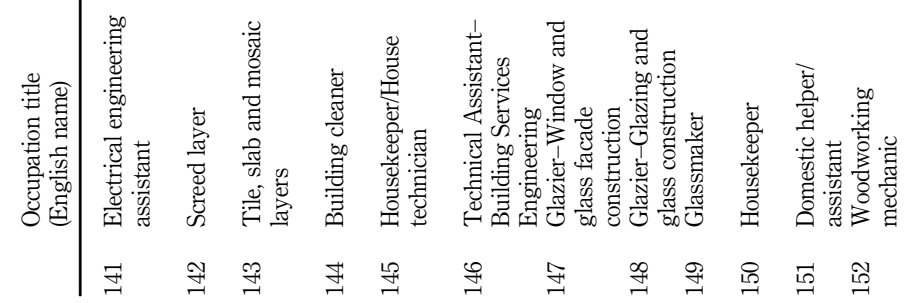




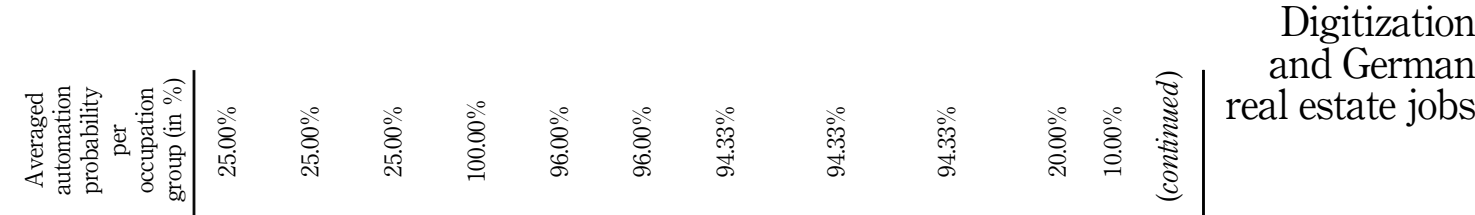

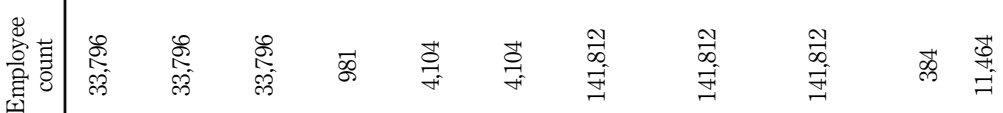

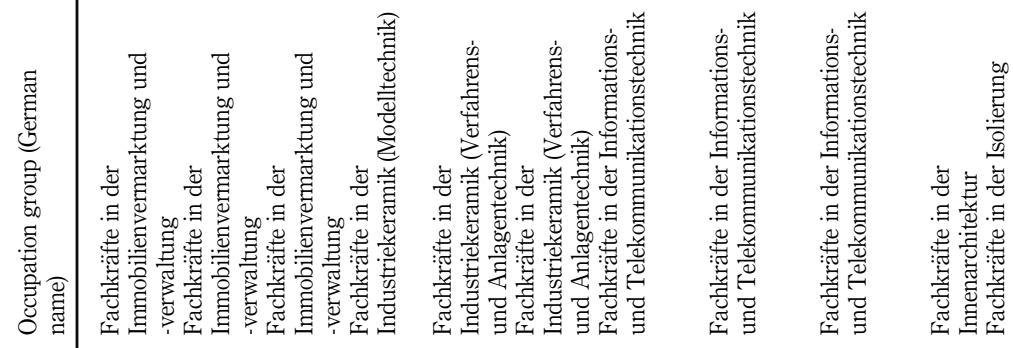

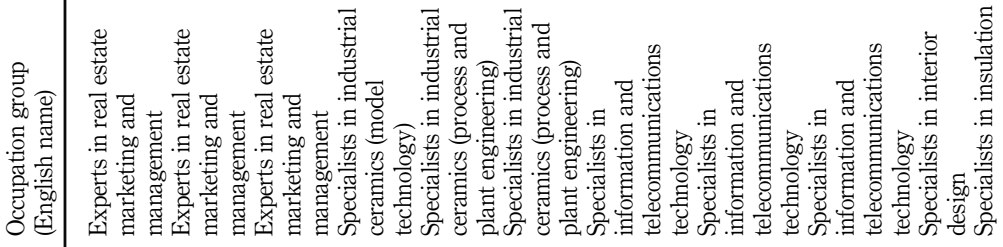

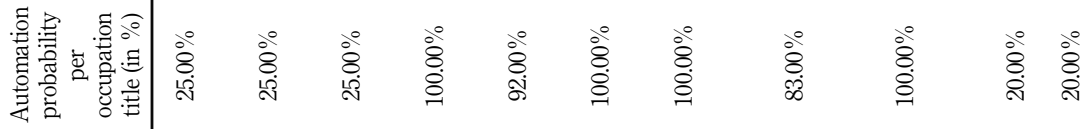

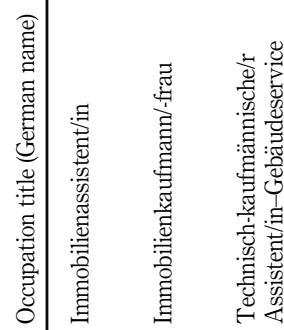

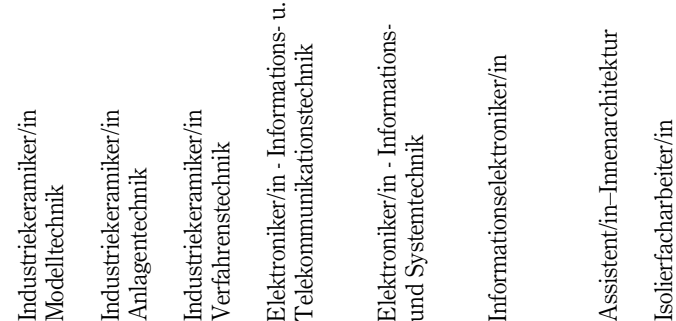

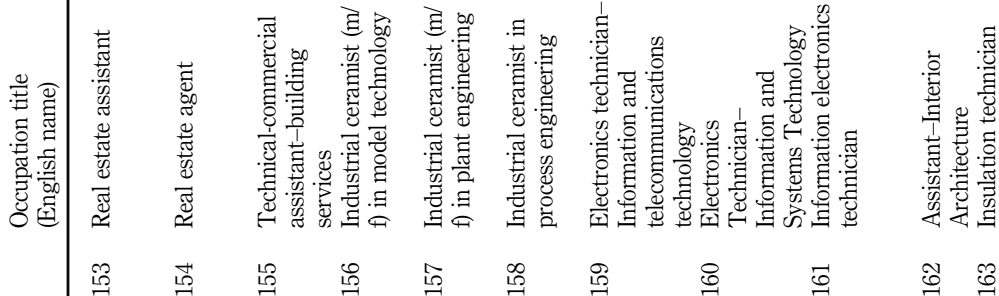

Table AI 


\section{JPIF \\ 39,2}

72

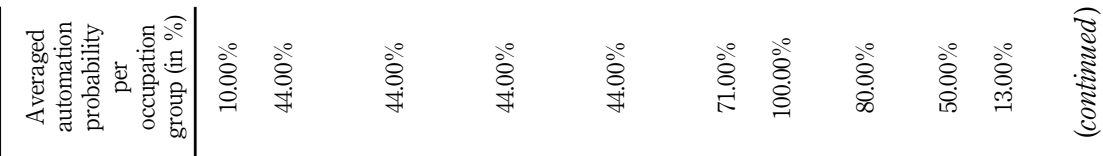

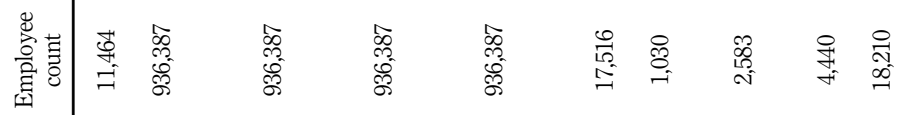

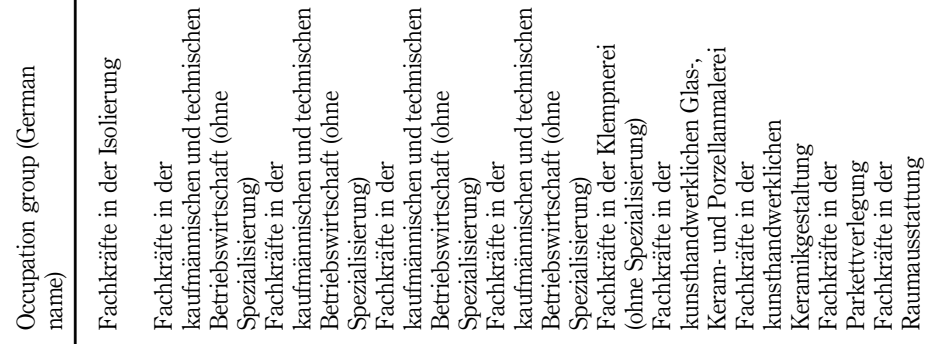

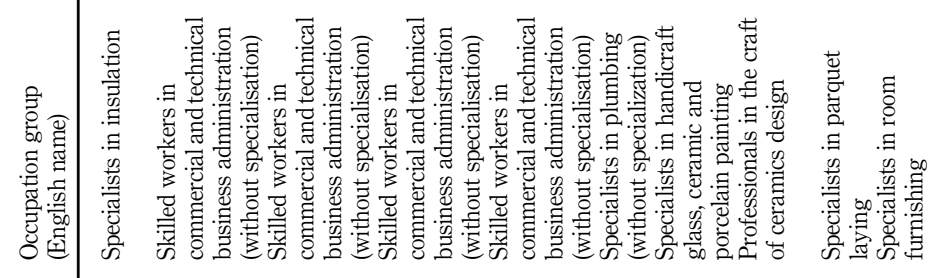

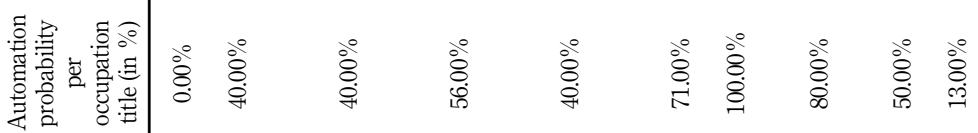

III

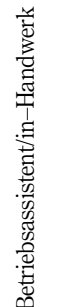

势

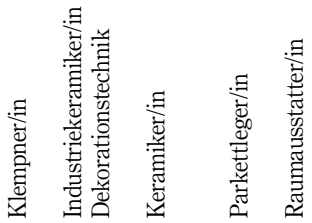

Table AI.

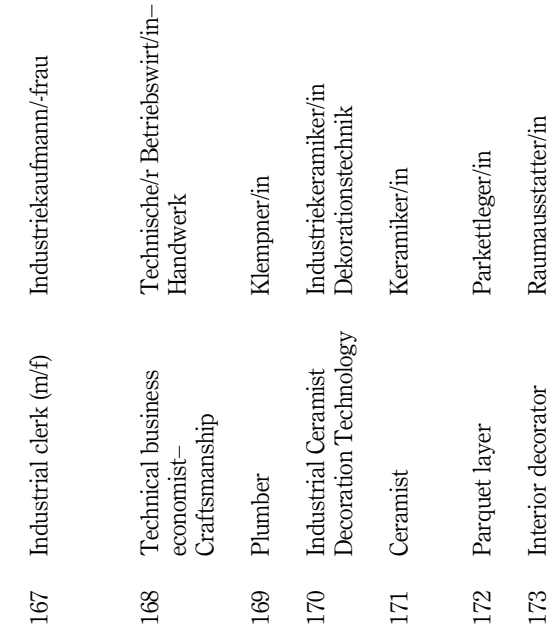

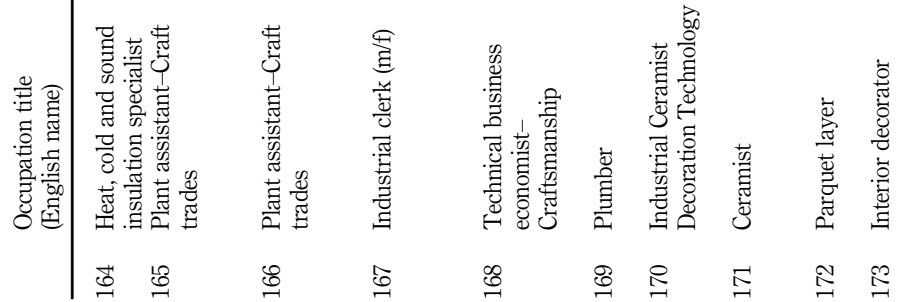




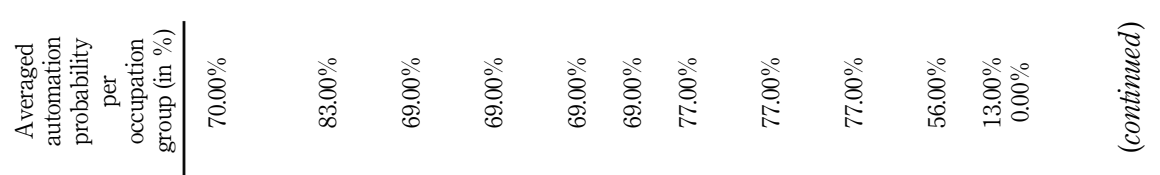

Digitization

and German real estate jobs

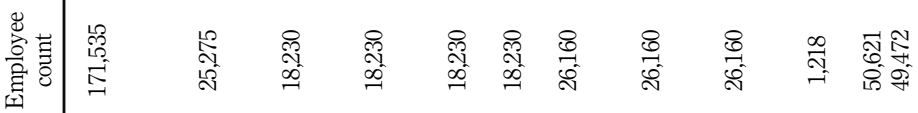

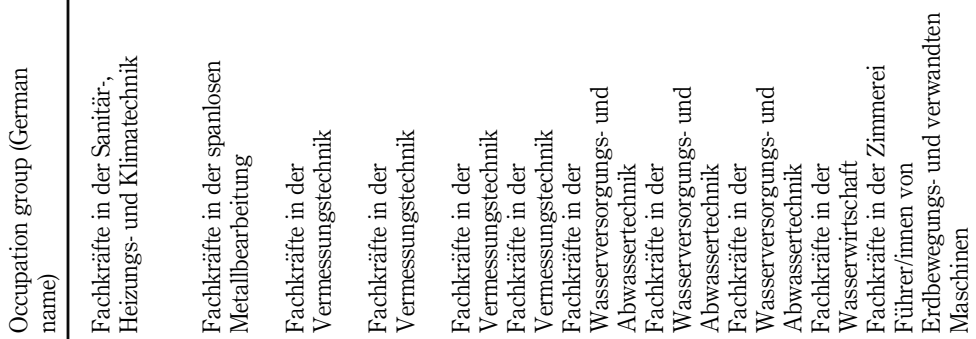

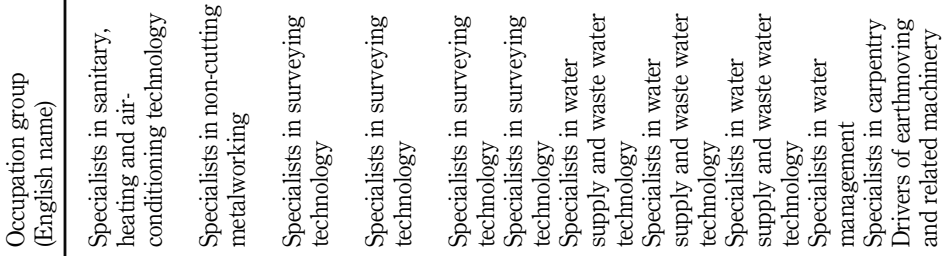

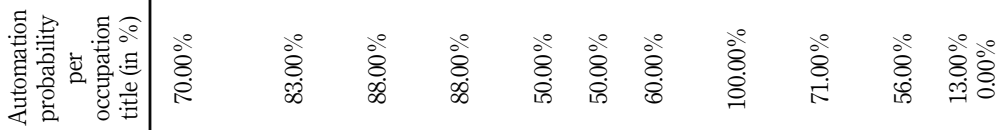

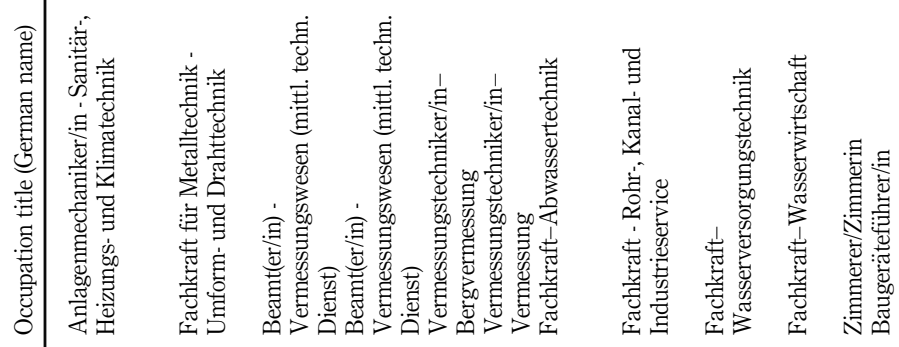

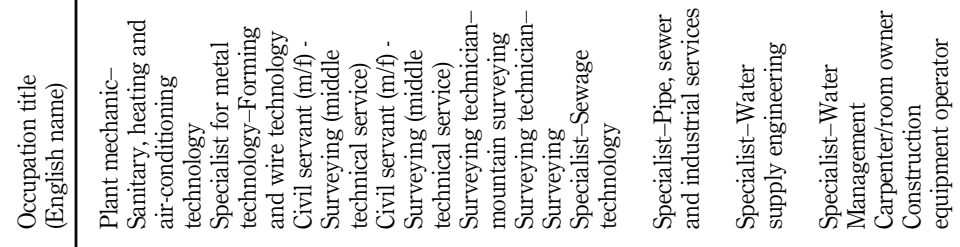

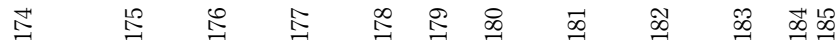

Table AI. 


\section{JPIF \\ 39,2}

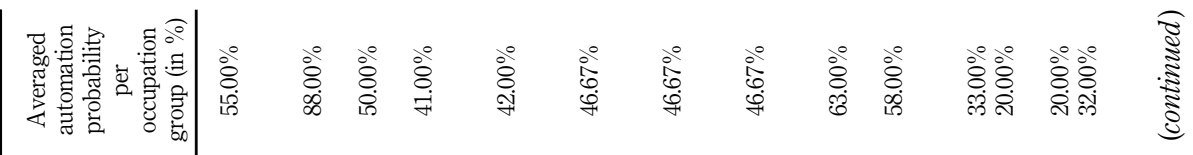

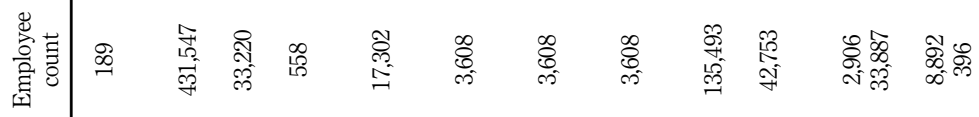

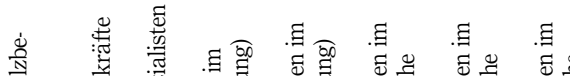

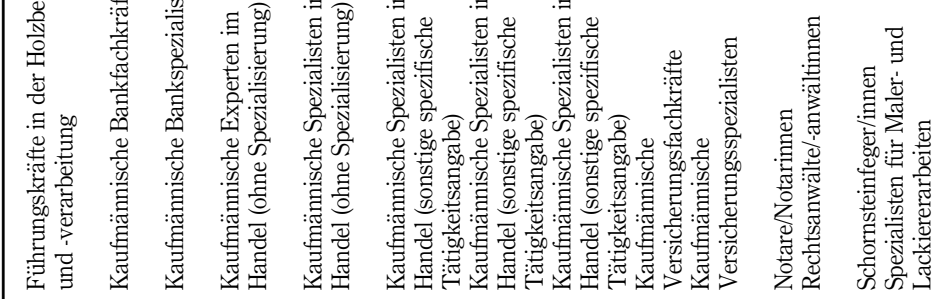

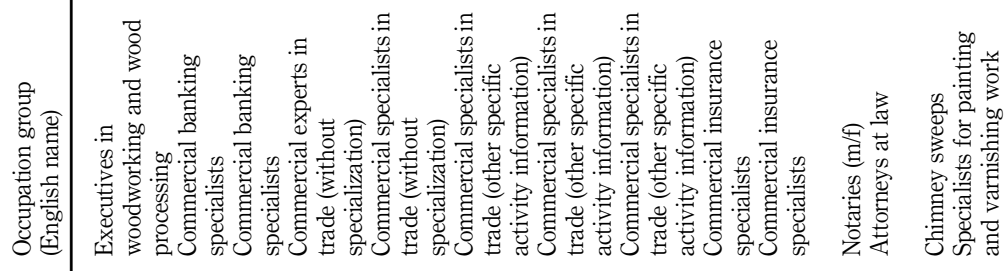

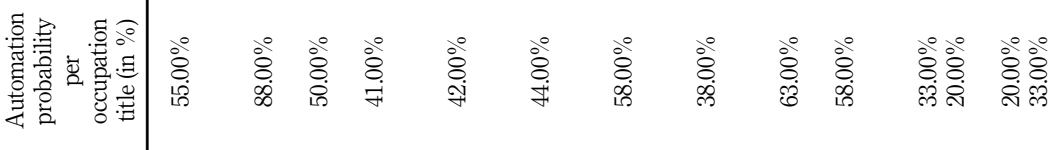




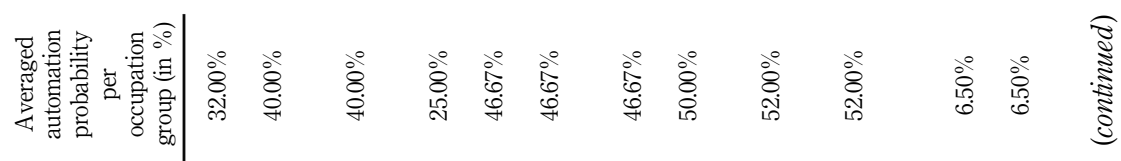

Digitization

and German real estate jobs

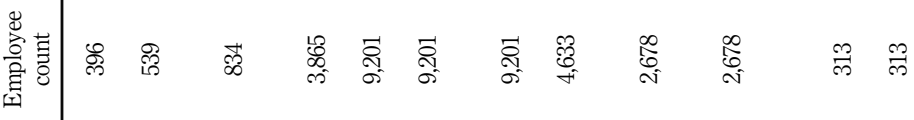

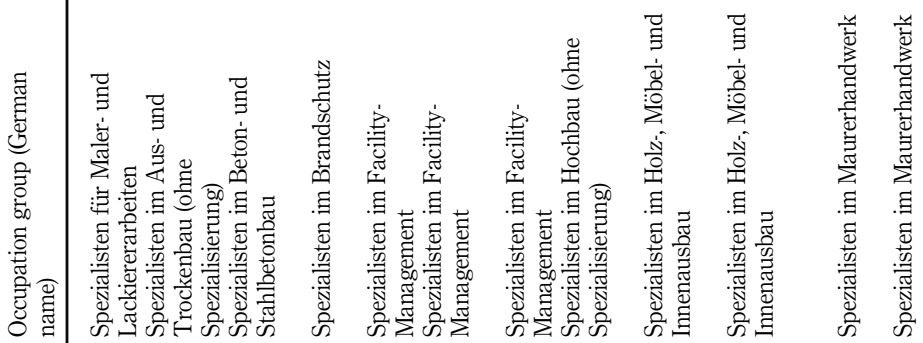

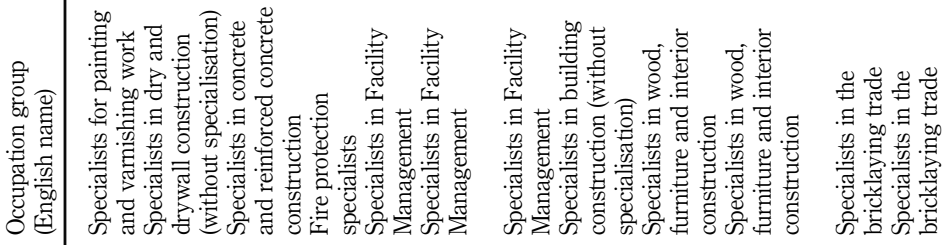

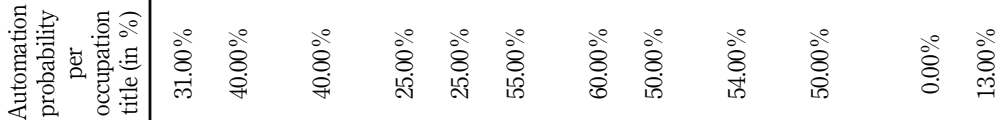

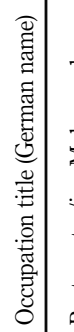

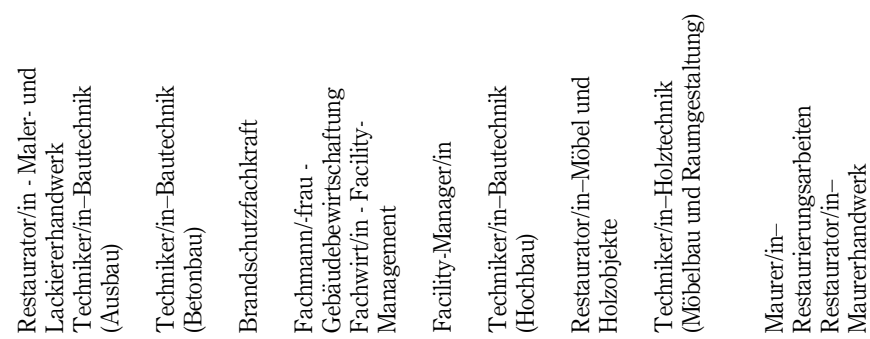

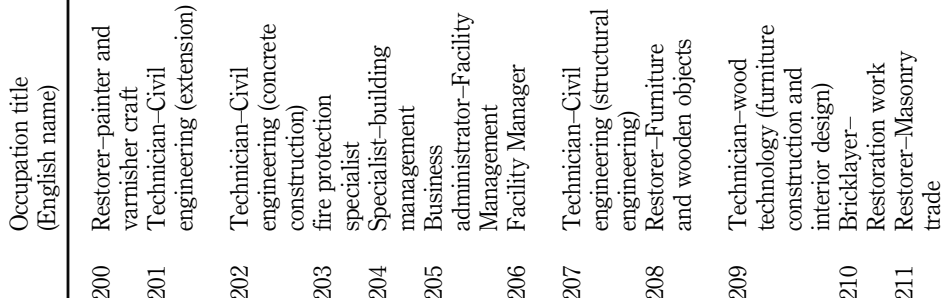

Table AI. 


\section{JPIF \\ 39,2}

76

$$
\begin{aligned}
& \text { Mfly }
\end{aligned}
$$

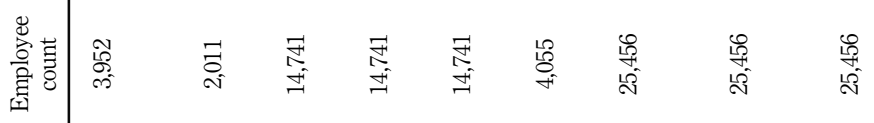

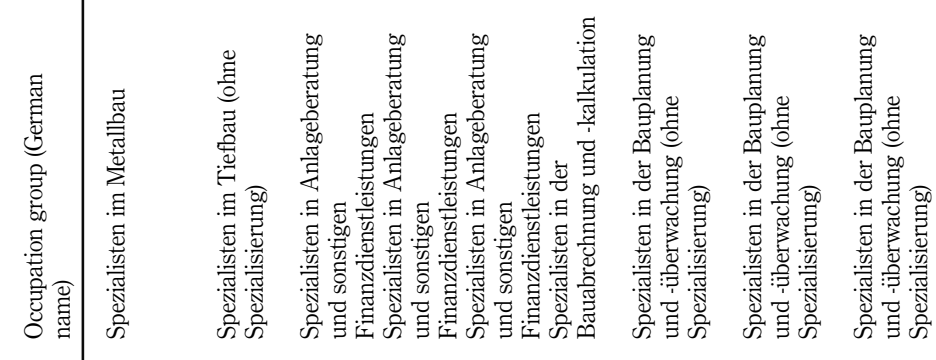

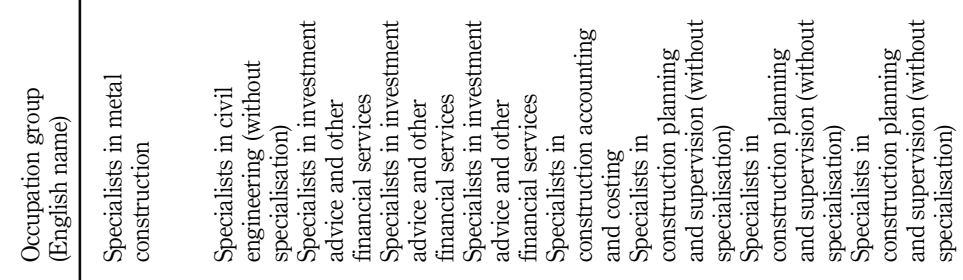

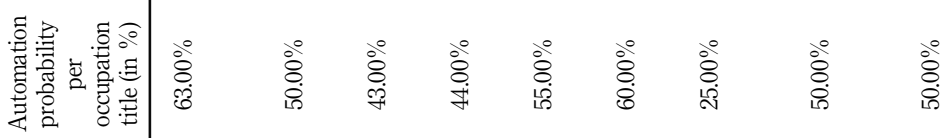

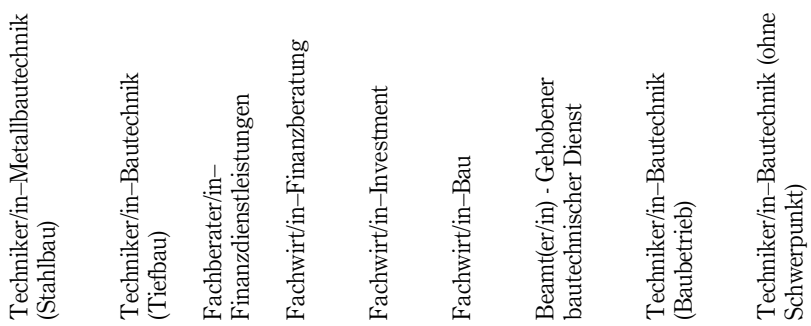

Table AI.

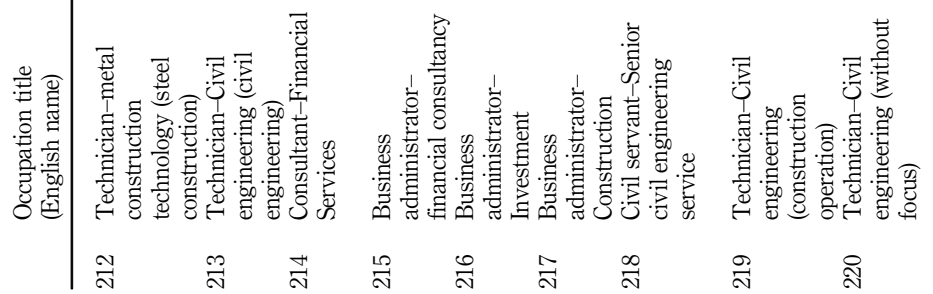




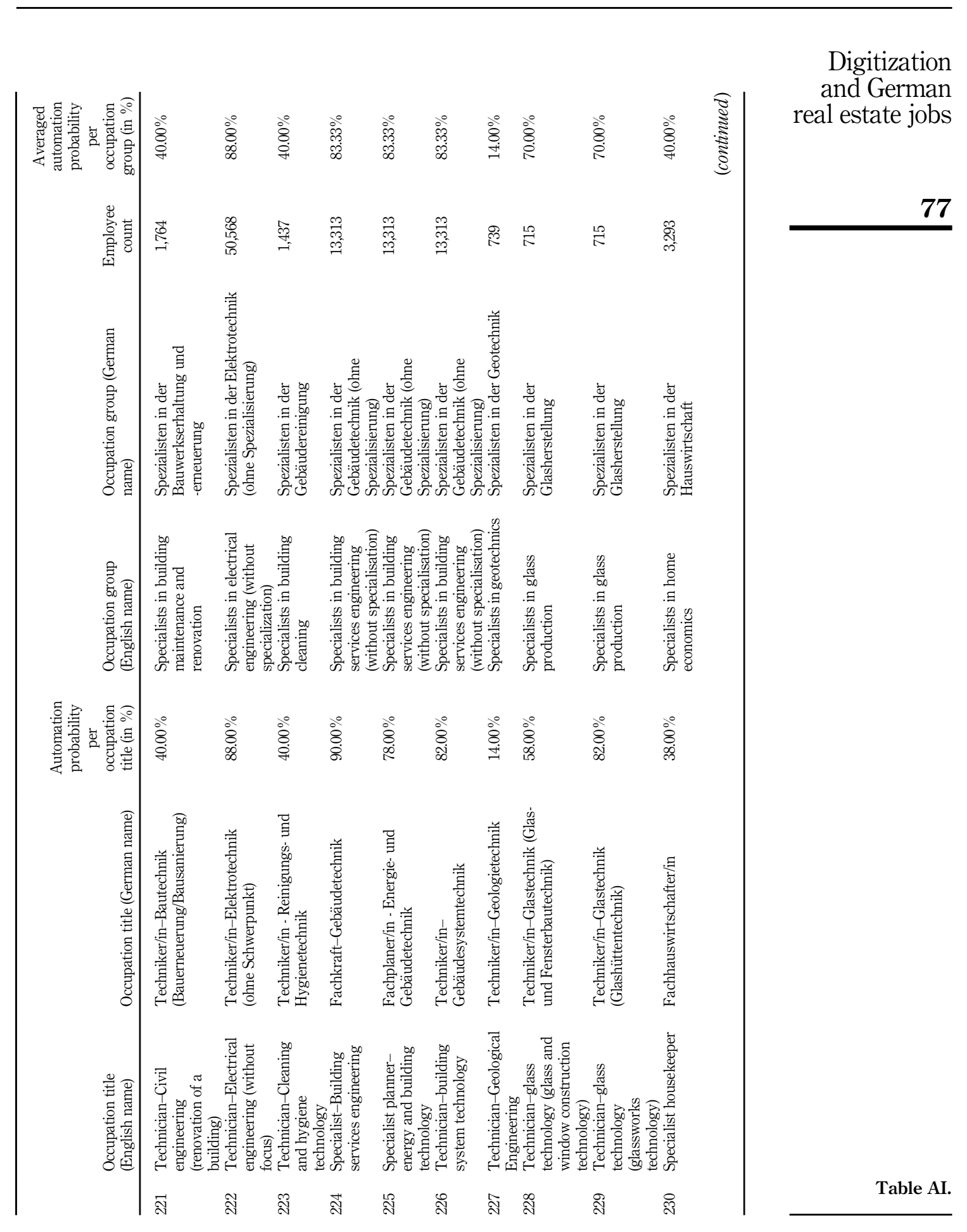




\section{JPIF \\ 39,2}

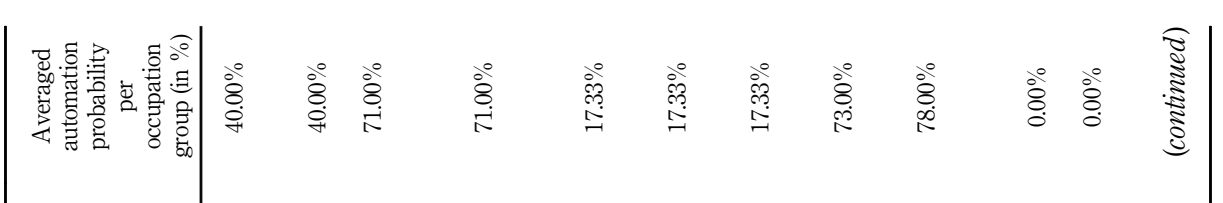

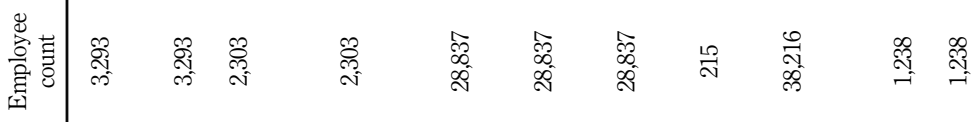

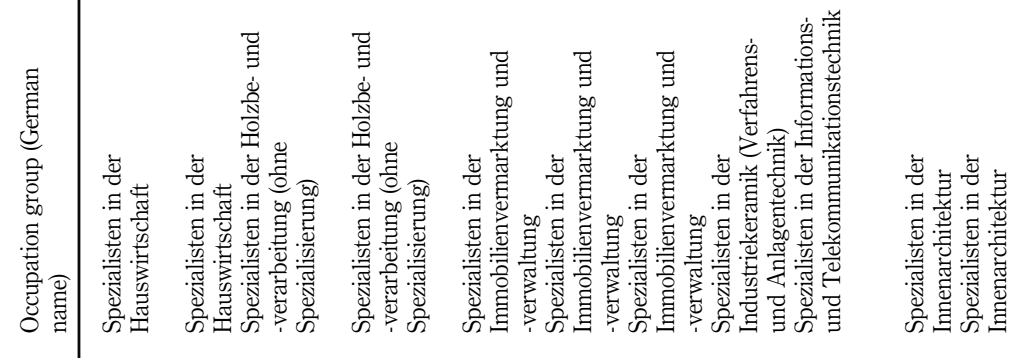

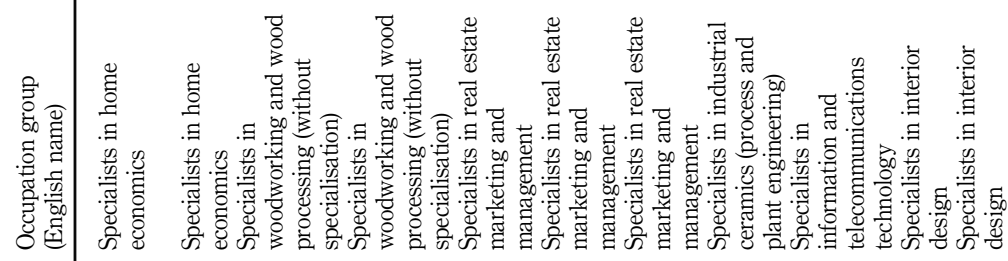

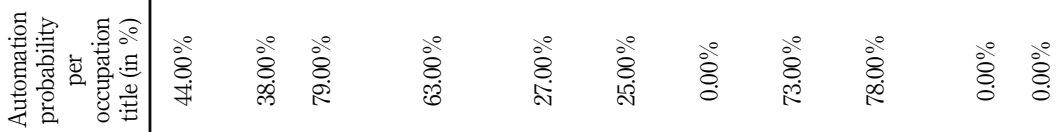

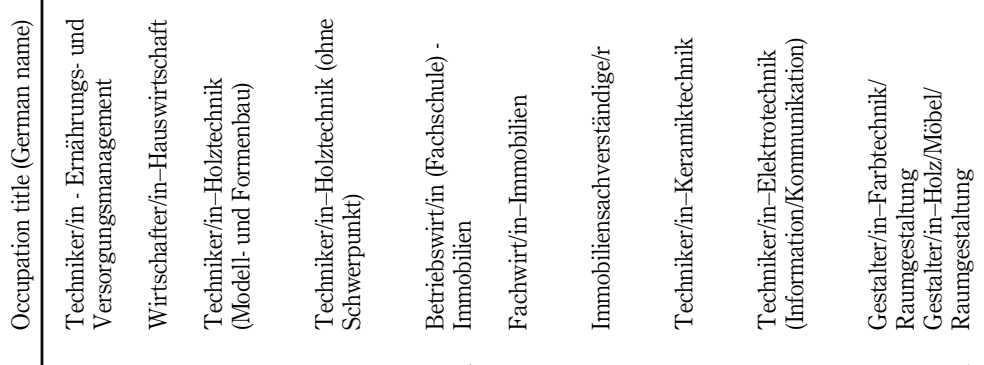

Table AI.

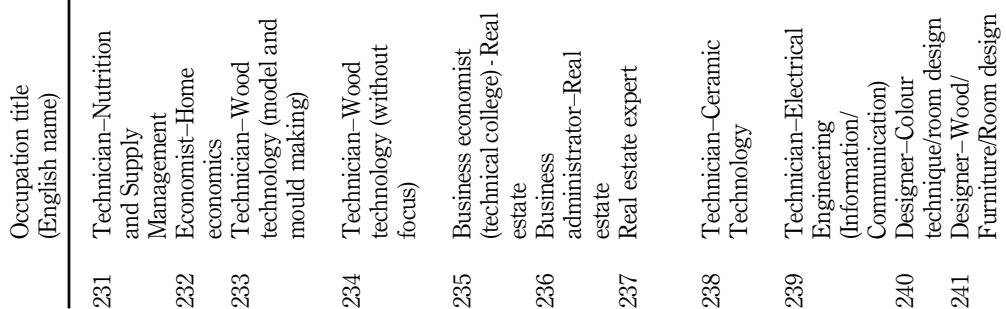




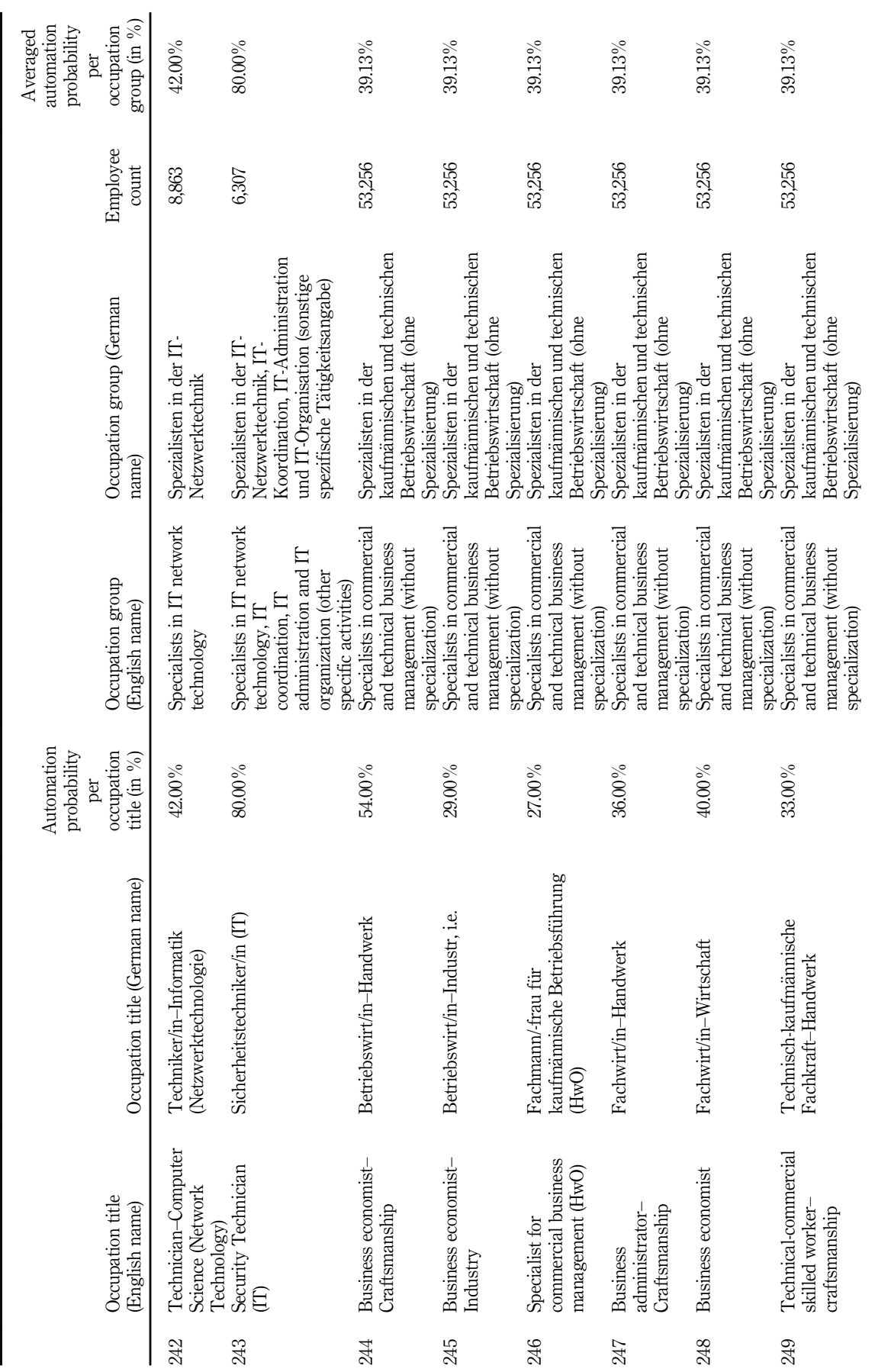

Digitization and German real estate jobs

79

Table AI. 
JPIF
39,2

80

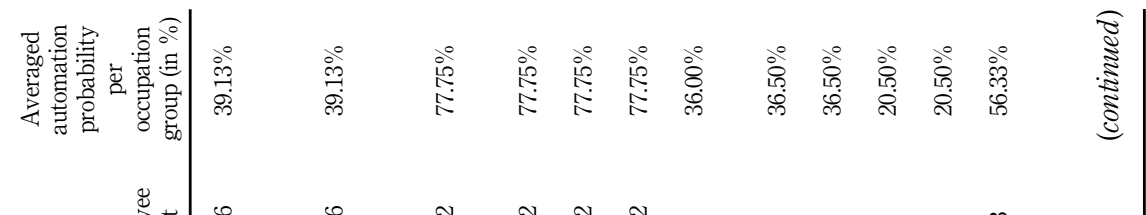

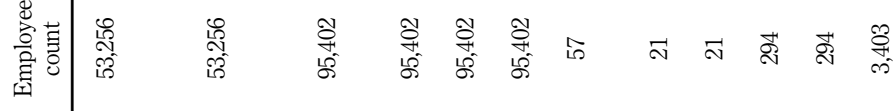

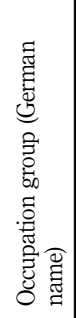

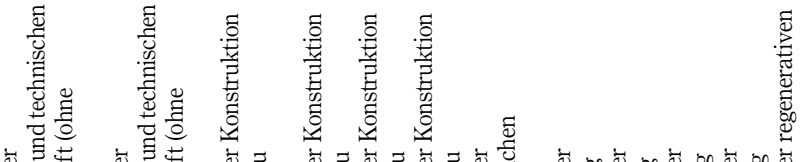

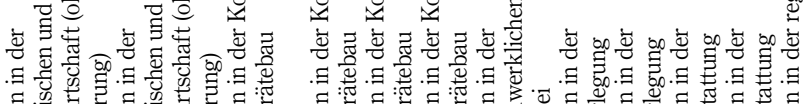

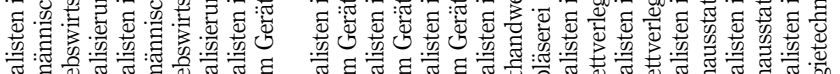

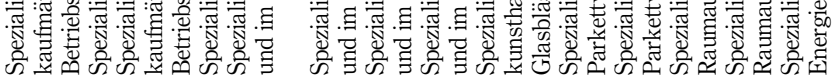

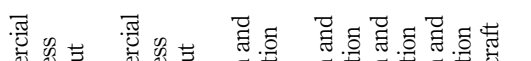

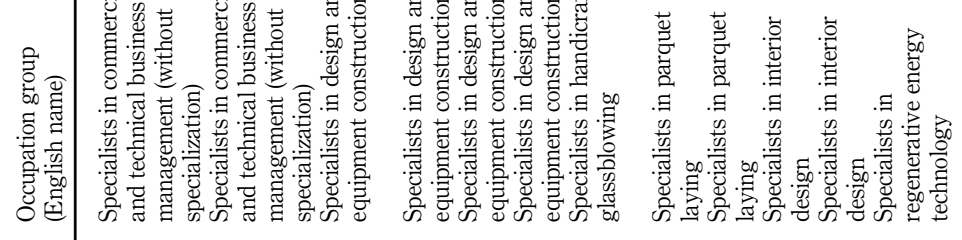

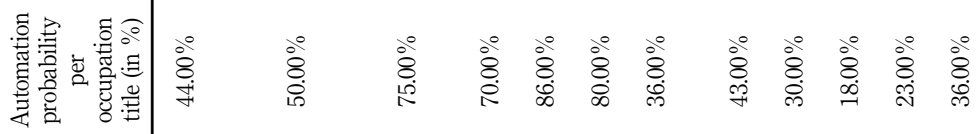

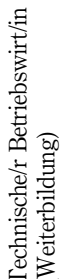
声

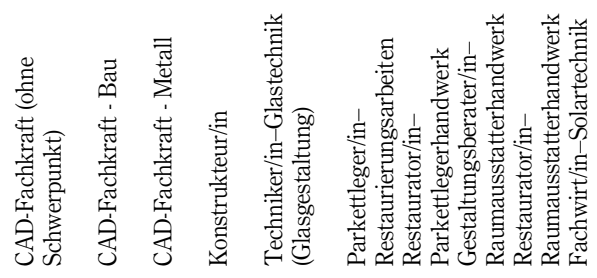

Table AI.

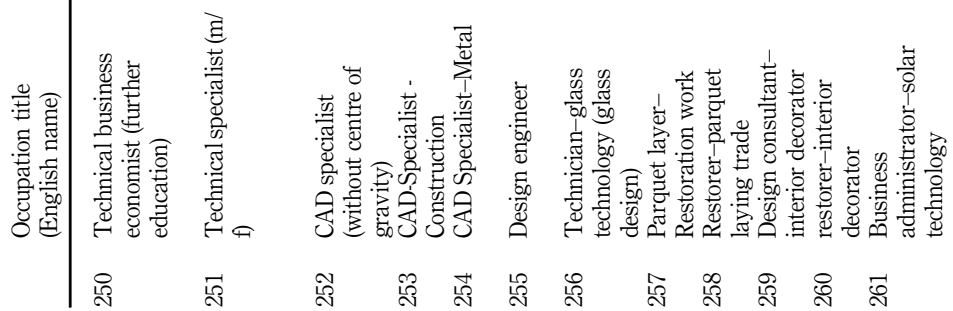




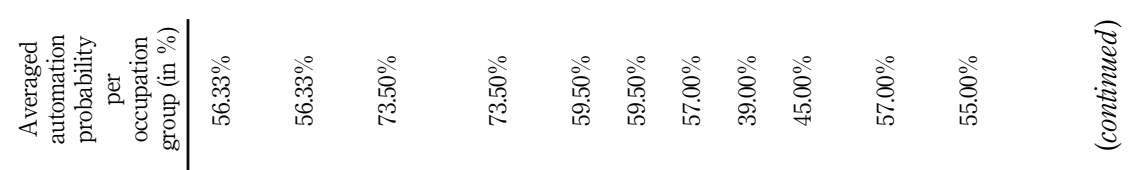

Digitization

and German

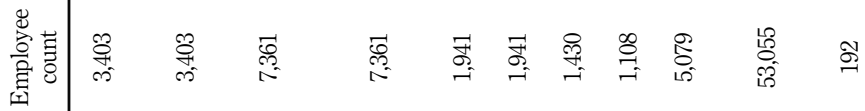

real estate jobs

81

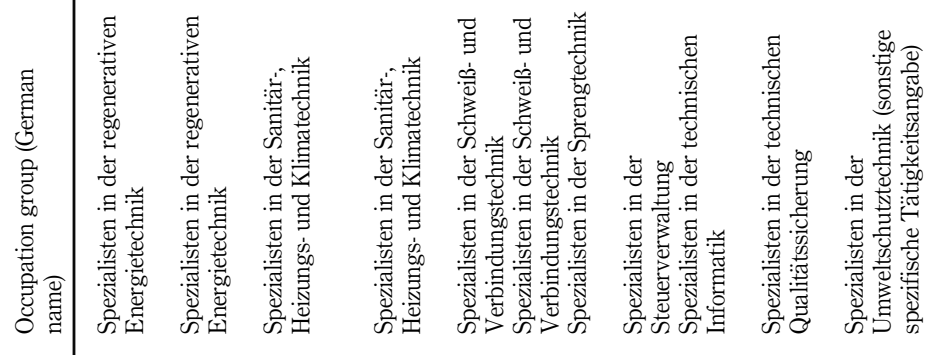

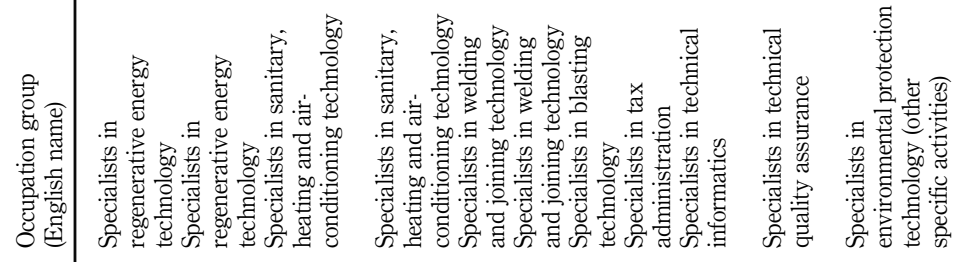

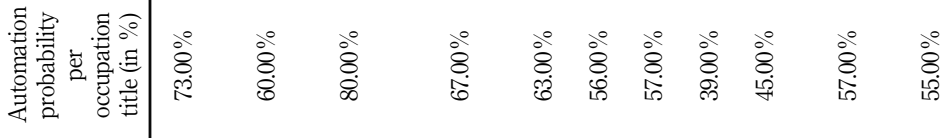

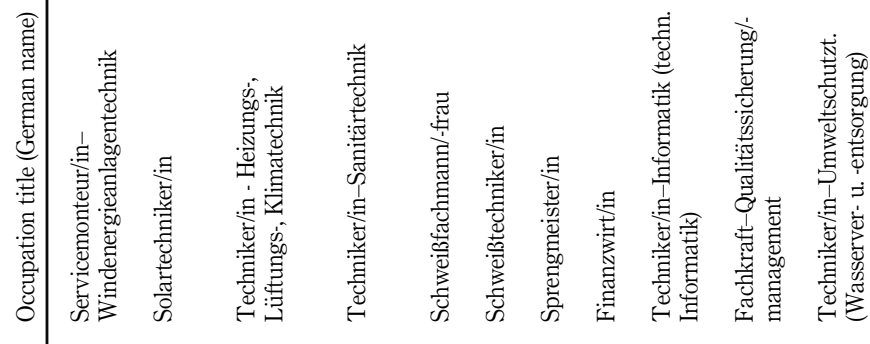

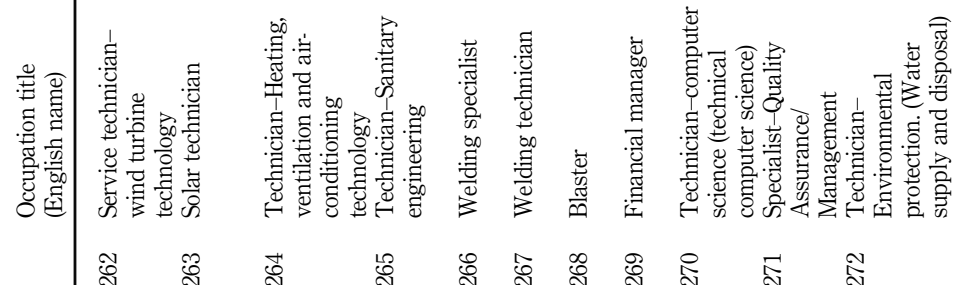

Table AI. 


\section{JPIF \\ 39,2}

82

$$
\begin{aligned}
& \text { Whenth }
\end{aligned}
$$

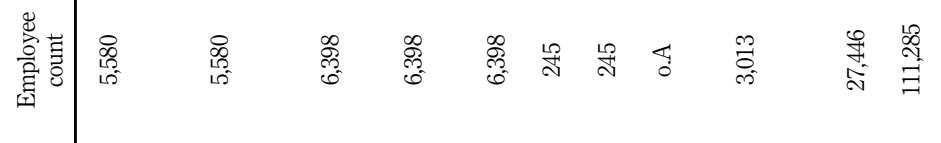

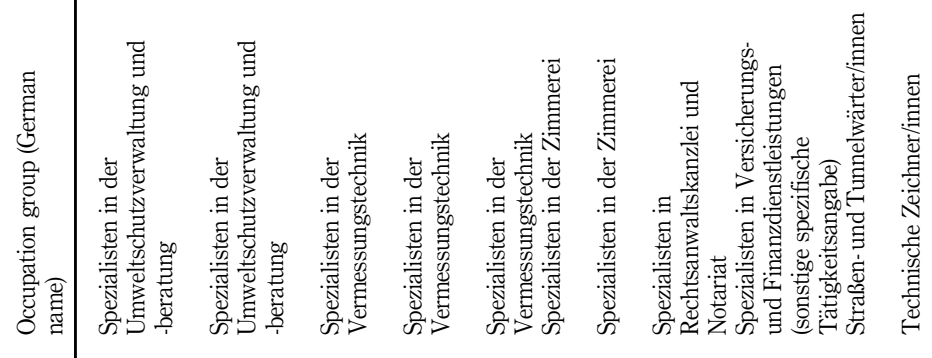

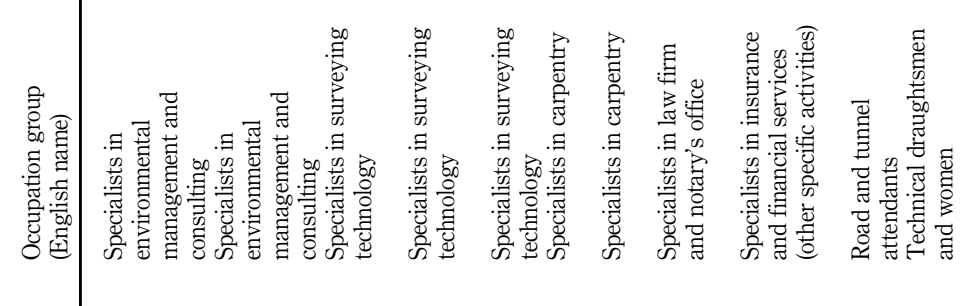

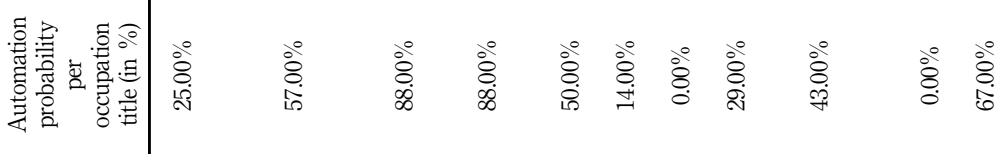

Table AI. 


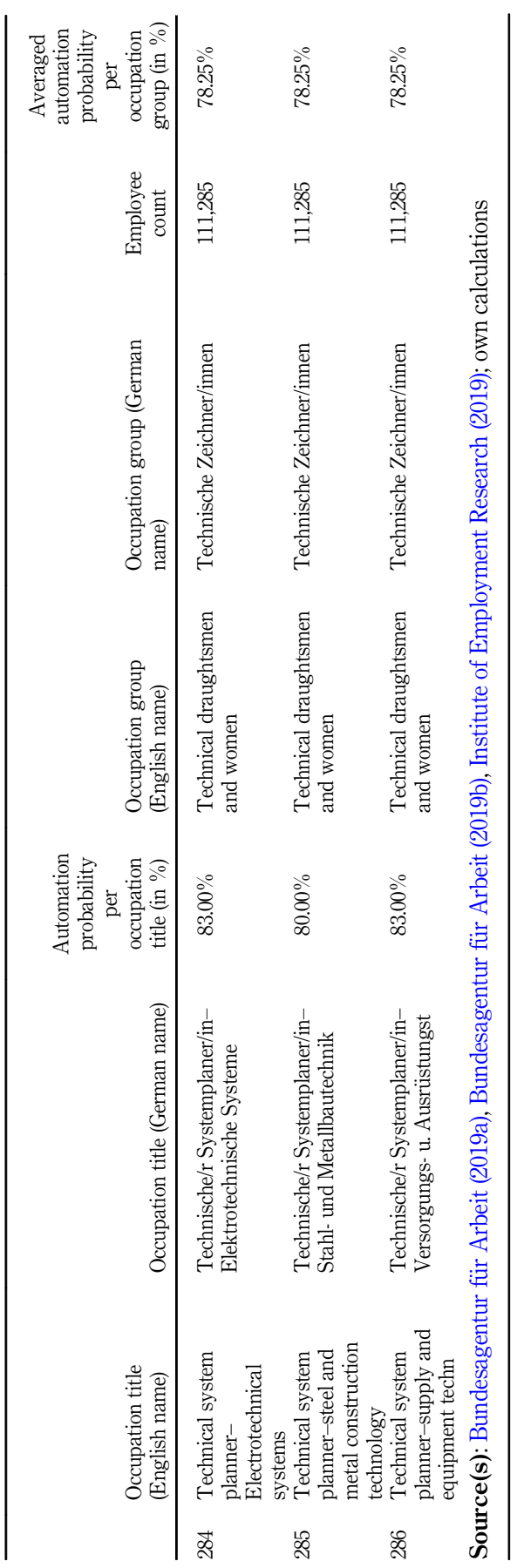

Digitization and German real estate jobs

83

Table AI. 